\title{
CLASSIFICAÇÃO DE IMAGENS DIGITAIS LANDSAT 8 NO SOFTWARE ENVI: Material teórico-prático
}

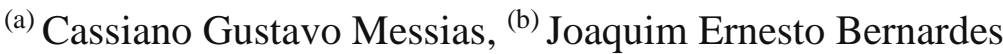

(a) Geógrafo (Unifal-MG), mestre em Geografia (Unicamp) e doutorando em Geografia (Unicamp). cassianomessiaslavras@gmail.com

(b) Geógrafo (Unifal-MG), mestre em Ecologia e Tecnologia Ambiental (Unifal-MG) e doutorando em Geociências (Unicamp).

\section{RESUMO}

Este texto compreende o material teórico-prático do minicurso ministrado no dia 28/07/2017, durante o XVII Simpósio Brasileiro de Geografia Física e Aplicada e I Congresso Nacional de Geografia Física e Aplicada, na cidade de Campinas SP.

Palavras-chave: ENVI, Sensoriamento Remoto, LANDSAT-8

\section{PARTE I}

\section{PRINCÍPIOS FÍSICOS DE SENSORIAMENTO REMOTO}

\section{MODELO ONDULATÓRIO DA ENERGIA ELETROMAGNÉTICA}

Nos anos 1960, James Clerck Maxwell concebeu a radiação eletromagnética (REM) como uma onda eletromagnética que se desloca pelo espaço à velocidade da luz. A onda eletromagnética possui dois campos flutuantes, um elétrico e outro magnético, estando em ângulos retos entre si e perpendiculares à direção do deslocamento da onda (JENSEN, 2009).

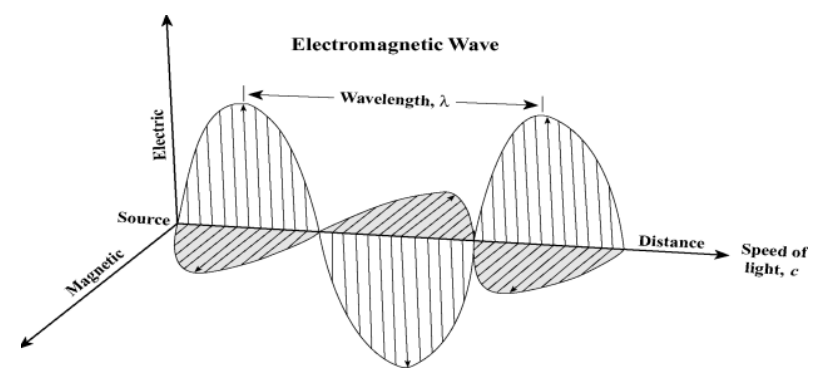




\section{OS DESAFIOS DA GEOGRAFIA FÍSICA NA FRONTEIRA DO CONHECIMENTO \\ Instituto de Geociências - Unicamp \\ Campinas - SP \\ 28 de Junho à 02 de Julho de 2017}

Fonte: Jensen (2009)

A REM é gerada toda vez que uma carga elétrica é acelerada. $\mathrm{O}$ comprimento de onda $(\lambda)$ depende da duração do tempo pelo qual a partícula foi acelerada. A frequência ( $v$ ) depende do número de acelerações por segundo. A frequência é inversamente proporcional ao comprimento de onda. A relação entre comprimento de onda $(\lambda)$, frequência $(v)$ e velocidade da luz $(c)$ pode ser descrita por:

$$
c=\lambda \cdot v \quad v=\frac{c}{\lambda} \quad \lambda=\frac{v}{c}
$$

O sol representa a fonte inicial da energia eletromagnética registrada pela maioria dos sistemas de sensores remotos passivos. A parte dessa energia que é interceptada pela terra e retorna ao espaço por reflexão ou emissão é de grande importância para o sensoriamento remoto (JENSEN, 2009).

\section{O ESPECTRO ELETROMAGNÉTICO}

No século XVII, Isaac Newton percebeu que um feixe de luz branca, ao atravessar um prisma, desdobrava-se em várias cores. Isto ocorre pois no momento em que atravessa o prisma, a luz branca, composta por vários comprimentos de onda, é refratada em diferentes ângulos (JENSEN, 2009). Denominamos espectro eletromagnético as regiões espectrais da REM, que representa todo o conjunto de comprimentos de ondas, variando dos raios gama até as ondas de rádio (MOREIRA, 2001). 


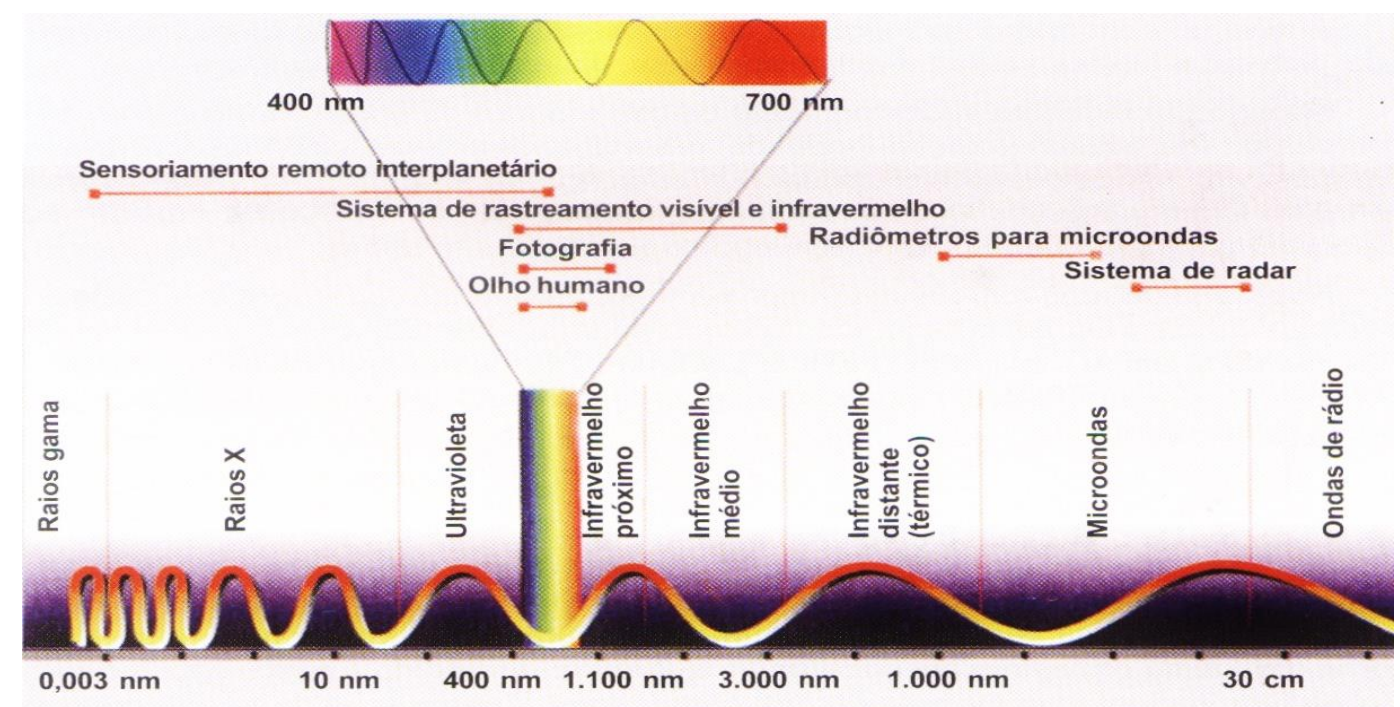

Fonte: Moreira (2011)

\section{INTERAÇÃO ENERGIA-MATÉRIA NO TERRENO}

A radiação eletromagnética proveniente do sol é a fonte de energia para a obtenção de imagens de sensoriamento remoto passivo (imagens de satélite, por exemplo). Ao interagirem com a atmosfera, há refração, espalhamento, absorção e reflexão (esses efeitos podem ser minimizados por técnicas de correção atmosférica). Após atingir os alvos terrestres, essa energia pode ser refletida, transmitida, absorvida e posteriormente emitida.

A reflectância é a capacidade de um certo objeto refletir a energia radiante (JENSEN, 2009). A reflectância de cada alvo depende de suas características físicas, variando de acordo com o alvo estudado. Várias geofácies terrestres podem ser reconhecidas e distinguidas pelas diferenças de quantidade de radiação refletida em função do comprimento de onda (MOREIRA, 2011).

A transmitância é a capacidade de um certo objeto transmitir a energia radiante. Absortância é a capacidade de um certo objeto absorver a energia radiante e convertê-la em outra forma de energia. Exemplo disso é a clorofila que absorve a luz do azul e vermelho para fins de fotossíntese. Emissividade $(\mathcal{E})$ é a razão entre a radiância real emitida por um corpo do 
muno real $\left(M_{r}\right)$ e um corpo negro à mesma temperatura cinética $\left(M_{b}\right)$. Todos os corpos que radiam seletivamente têm emissividade variando entre $0 \leq 1$ (JENSEN, 2009).

A energia refletida ou emitida são recebidas pelo sensor, que as envia para estações receptoras e transforma-a em valores digitais, os quais formam as imagens.

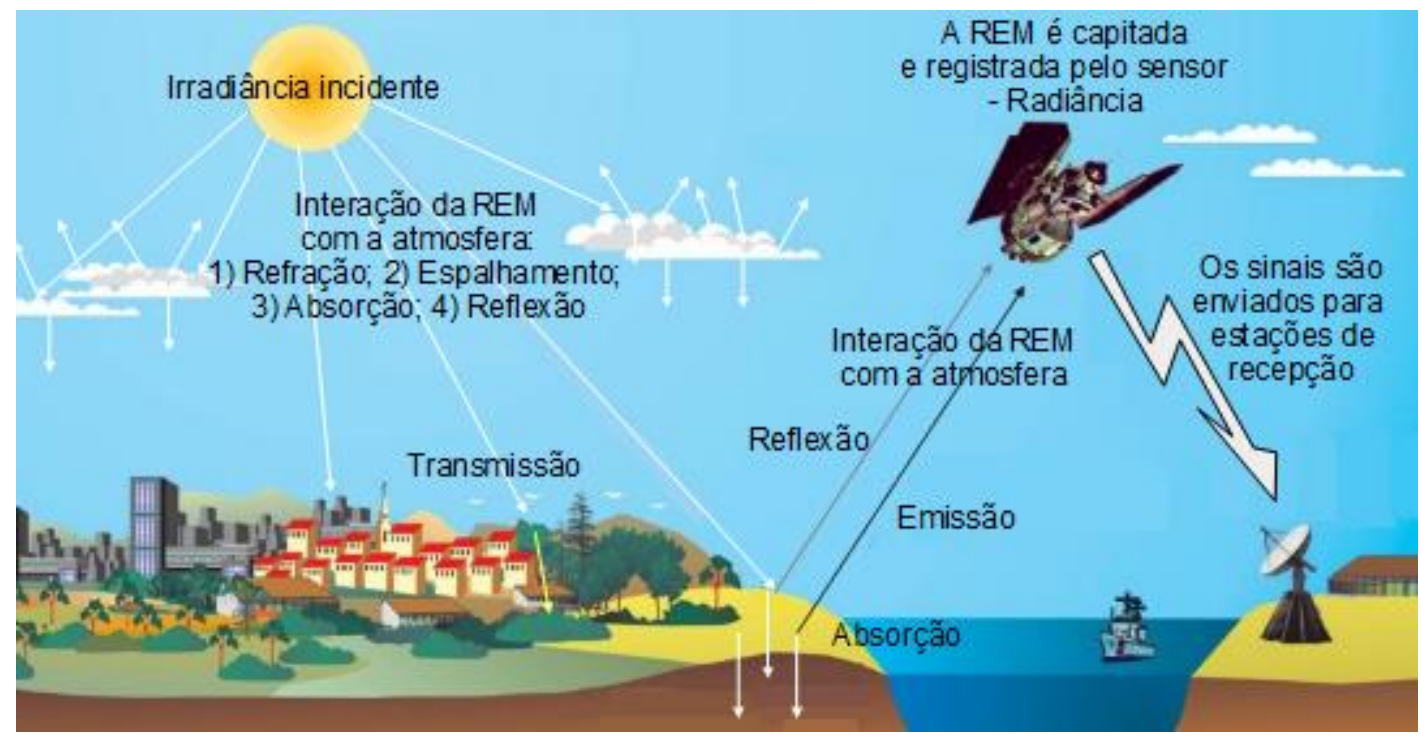

Fonte: adaptado de Florenzano (2011)

\section{CARACTERÍSTICAS DE IMAGENS MULTIESPECTRAIS}

As imagens multiespectrais são formadas por diferentes bandas (canais), os quais estão relacionados à reflectância dos alvos em diferentes faixas do espectro eletromagnético (no caso do infravermelho termal, emitância). As imagens digitais são formadas por pixels de diferentes valores, os quais estão associados à reflectância (ou emitância). Esses valores são chamados de número digital (digital numember - DN) ou nível de cinza. Uma imagem de 8 bits possui 256 níveis de cinza, que variam do preto (0) ao branco (255). 


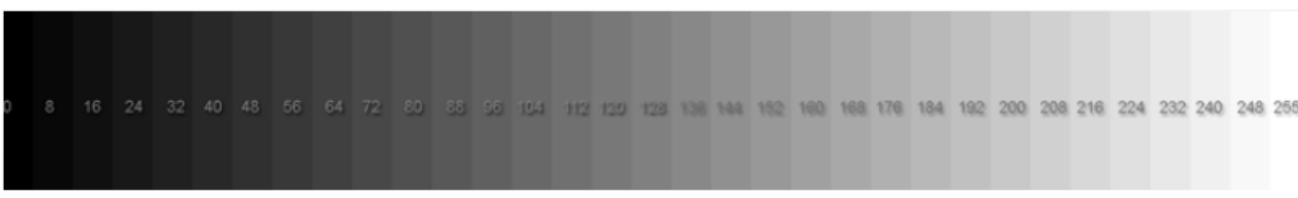

Absorve energia eletromagnética

$<$ nível de cinza (Próximo de 0 )
Reflete energia eletromagnética $>$ nível de cinza (Próximo de 255)

\section{CARACTERÍSTICAS DAS IMAGENS LANDSAT 8}

Neste curso, trabalharemos com imagens Landsat 8, do sensor Operational Land Imager (OLI). O sensor OLI opera nas faixas relacionadas ao sensoriamento remoto reflexivo. O sensor OLI possui bandas espectrais para coleta de dados na faixa do visível, infravermelho próximo e infravermelho de ondas curtas, além de uma banda pancromática.

\begin{tabular}{|c|c|c|c|c|c|c|}
\hline Sensor & Bandas Espectrais & $\begin{array}{c}\text { Resolução } \\
\text { Espectral }\end{array}$ & $\begin{array}{c}\text { Resolução } \\
\text { Espacial }\end{array}$ & $\begin{array}{c}\text { Resolução } \\
\text { Temporal }\end{array}$ & $\begin{array}{c}\text { Área } \\
\text { Imageada }\end{array}$ & $\begin{array}{c}\text { Res. } \\
\text { Radiométrica }\end{array}$ \\
\hline \multirow{9}{*}{$\begin{array}{l}\text { OLI (Operational } \\
\text { Land Imager) }\end{array}$} & (B1) COSTAL & $\begin{array}{c}0.433-0.453 \\
\mu \mathrm{m}\end{array}$ & \multirow{7}{*}{$30 \mathrm{~m}$} & \multirow{9}{*}{16 dias } & \multirow{9}{*}{$185 \mathrm{~km}$} & \multirow{9}{*}{16 bits } \\
\hline & (B2) AZUL & $\begin{array}{c}0.450-0.515 \\
\mu \mathrm{m}\end{array}$ & & & & \\
\hline & (B3) VERDE & $\begin{array}{c}0.525-0.600 \\
\mu \mathrm{m}\end{array}$ & & & & \\
\hline & (B4) VERMELHO & $\begin{array}{c}0.630-0.680 \\
\mu \mathrm{m}\end{array}$ & & & & \\
\hline & $\begin{array}{c}\text { (B5) INFRAVERMELHO } \\
\text { PRÓXIMO }\end{array}$ & $\begin{array}{c}0.845-0.885 \\
\mu \mathrm{m}\end{array}$ & & & & \\
\hline & $\begin{array}{l}\text { (B6) INFRAVERMELHO } \\
\text { MÉDIO }\end{array}$ & $\begin{array}{c}1.560-1.660 \\
\mu \mathrm{m}\end{array}$ & & & & \\
\hline & $\begin{array}{l}\text { (B7) INFRAVERMELHO } \\
\text { MÉDIO }\end{array}$ & $\begin{array}{c}2.100-2.300 \\
\mu \mathrm{m}\end{array}$ & & & & \\
\hline & (B8) PANCROMÁTICO & $\begin{array}{c}0.500-0.680 \\
\mu \mathrm{m}\end{array}$ & $15 \mathrm{~m}$ & & & \\
\hline & (B9) Cirrus & $\begin{array}{c}1.360-1.390 \\
\mu \mathrm{m}\end{array}$ & $30 \mathrm{~m}$ & & & \\
\hline
\end{tabular}

Fonte: Embrapa Monitoramento por Satélite (2017)

\section{IMPORTANDO DIFERENTES BANDAS MULTIESPECTRAIS NO ENVI}

A. Abra o ENVI na versão atual disponível (não utilize a versão clássica). 
B. Queremos visualizar diversas bandas, uma ao lado da outra, para perceber as diferenças entre elas.

C. No ENVI, clique em Views > 3x3 viewes.

D. Em cada uma das janelas será importada uma banda de uma imagem Landsat OLI. Essa banda foi recortada para facilitar a compreensão das técnicas que serão apresentadas. Esse recorte abrange uma área do município de Alfenas, situado no sul de Minas Gerais (órbita/ponto 219/75, de 02/05/2016). Para importar uma banda, selecione o primeiro quadro da tela, para ser importada a banda 1 .

E. Clique em File > Open > Na pasta do curso, dê clique duplo no arquivo que contém as bandas 1 a 7 do sensor OLI empilhadas. Obs.: para realizar esse empilhamento de bandas, no Toolbox clique em Raster management > Layer stacking.

F. Será aberta a janela Data manager. Verifique que será aberta uma janela que lista todas as bandas empilhadas no arquivo, do costal ao infravermelho médio 2.

G. Vamos importar primeiramente a banda 1, costal. Selecione a banda Costal > clique em Load gray scale. Repita os procedimentos para as oito bandas, importando uma em cada quadro na ordem.

H. Para visualizar a mesma área em todos os quadros, associados às diferentes bandas, clique em Views > Link views.

I. Clique sobre todas as imagens, habilitando-as > OK. Verifique que ao mover ou dar zoom em qualquer banda, em todas as outras será feito o mesmo.

\section{FAZENDO LEITURA DO NÍVEL DE CINZA DO PIXEL EM IMAGENS LANDSAT 8}

A. Para se fazer a leitura do nível de cinza de um pixel na imagem, pode-se utilizar o botão Cursos value

B. Como os produtos do Landsat 8 apresentam-se em 16 bits, as imagens são expressas em aproximadamente 36.000 níveis de cinza. Então, quanto mais próximo de 0 o valor, mais escuro será o pixel e o alvo tem baixa reflectância. Por outro lado, quanto mais próximo de 36.000 mais claro será o pixel e o alvo tem alta reflectância. 
XVII Simpósio Brasileiro de Geografia Física Aplicada

I Congresso Nacional de Geografia Física
OS DESAFIOS DA GEOGRAFIA FÍSICA NA FRONTEIRA DO CONHECIMENTO

Instituto de Geociências - Unicamp

Campinas - SP

28 de Junho à 02 de Julho de 2017

C. Dentro do Cursos value pode-se habilitar a função Show info for top layer only para apresentar o valor para todas as bandas do arquivo que contém todas as bandas.

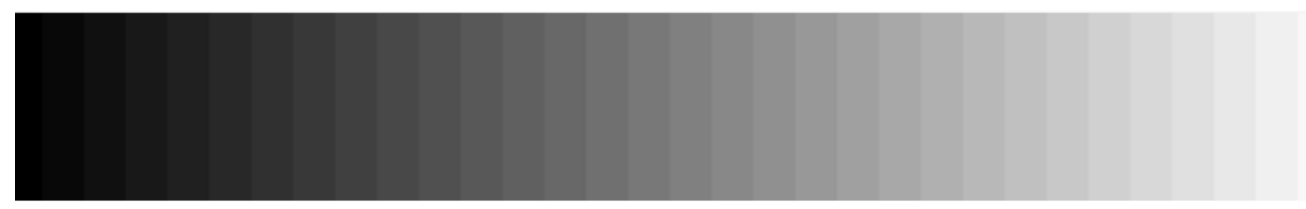

Absorve energia eletromagnética

Reflete energia eletromagnética

$<$ nível de cinza (Próximo de 0)

> nível de cinza (Próximo de 36.000)

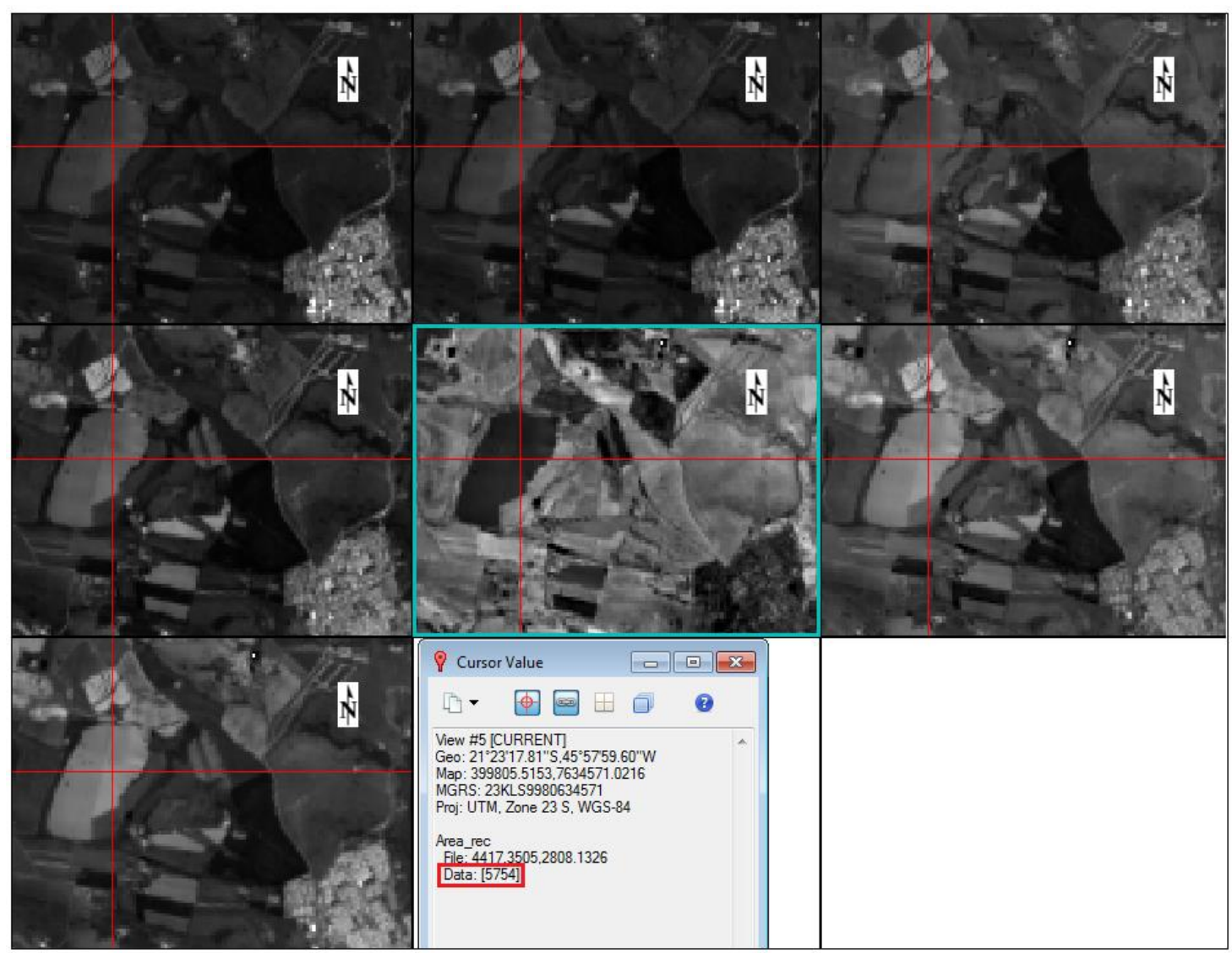




\section{PARTE II}

\section{COMPOSIÇÕES COLORIDAS}

\section{O QUE SÃO COMPOSIÇÕES COLORIDAS}

As imagens digitais coloridas são associação entre bandas originais (ou canais) e filtros coloridos Vermelho (Red) / Verde (Green) / Blue (Azul). As composição cor verdadeira são aquela em que a banda do vermelho é associada ao filtro vermelho, do verde ao filtro verde e do azul ao filtro azul. As composição falsa cor são aquela em que a banda não é associada à cor do filtro.
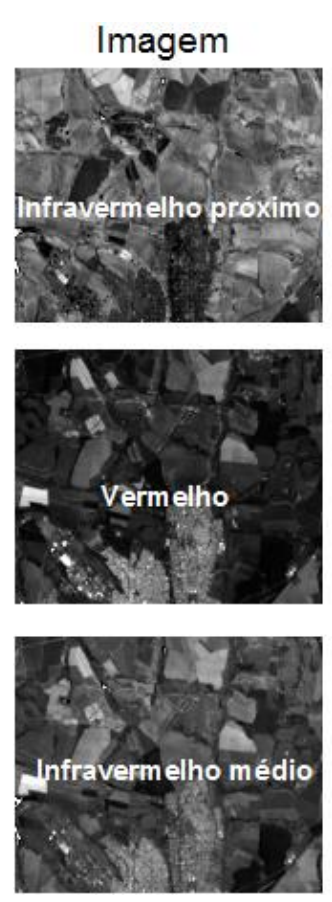
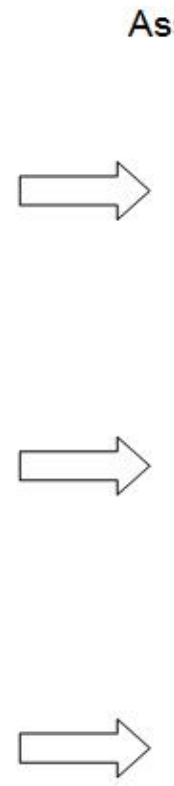

Associação imagem + filtro
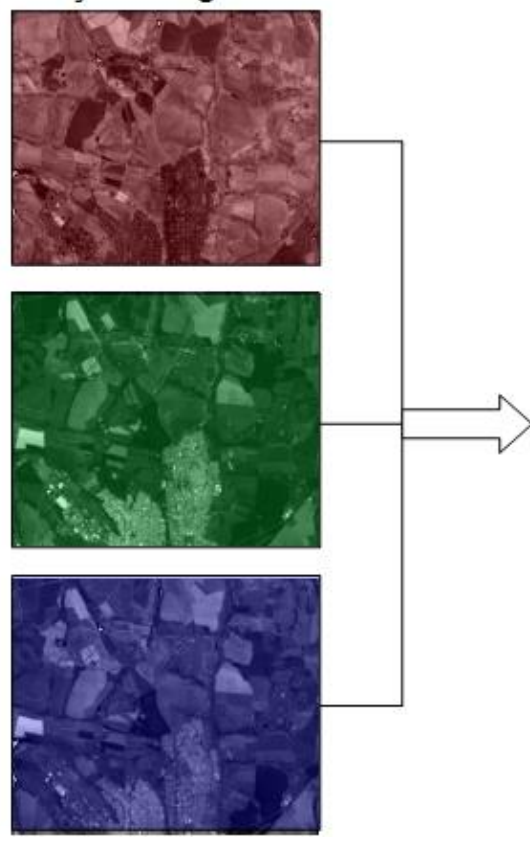

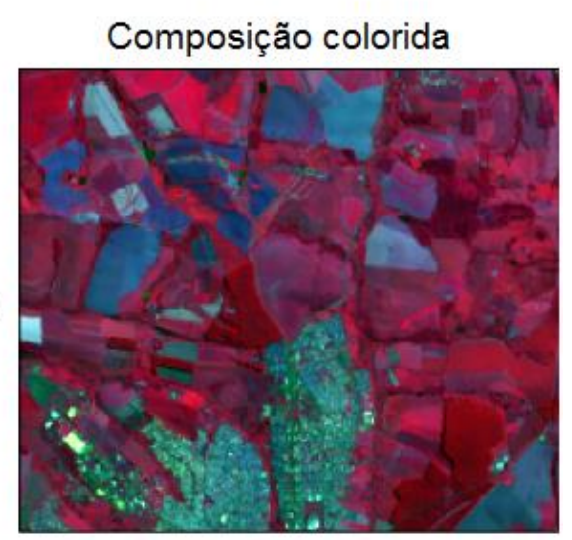

\section{COMO ASSOCIAR COMPOSIÇÕES COLORIDAS AOS FILTROS}

Ao associarem bandas das imagens multiespectrais aos filtros podem-se gerar diferentes resultados de composições falsa cor. Esses resultados estão relacionados aos níveis de 
reflectância nas diferentes bandas. Algumas considerações podem auxiliar no entendimento da geração de composições coloridas falsa cor:

A) Se uma cobertura do solo tem pixels claros em três bandas (alto nível de cinza), então ela será branca na composição colorida. Exemplo: nuvem considerando uma composição cor verdadeira.

B) Se uma cobertura do solo tem pixels escuros nas três bandas (baixo nível de cinza), então ela será preta na composição colorida. Exemplo: água com baixo teor de umidade na composição R5/G4/B6.

C) Se uma cobertura do solo tem pixels escuros em duas das bandas (baixo nível de cinza) e claros em uma banda (alto nível de cinza), então ela assumirá a cor do filtro atribuído à banda onde os pixels são brancos. Exemplo: a vegetação fica em tons avermelhados na composição R5/G4/B6. A vegetação reflete muito na banda 5, onde foi aplicado o filtro vermelho e pouco na 4 e 6 .

D) Se uma cobertura do solo tem pixels escuros em uma banda (baixo nível de cinza) e claros em duas bandas (alto nível de cinza), então será feita uma mistura das cores dos filtros atribuído às bandas onde os pixels são brancos. Exemplo: solo exposto fica em tons próximos de ciano (verde + azul), pois reflete bastante na banda 4 (filtro verde) e 6 (banda azul) na composição R5/G4/B6. Por outro lado, reflete pouco na banda 5.

Então, considerando níveis de reflectância estejam em uma escala entre 0 (reflete pouco) e

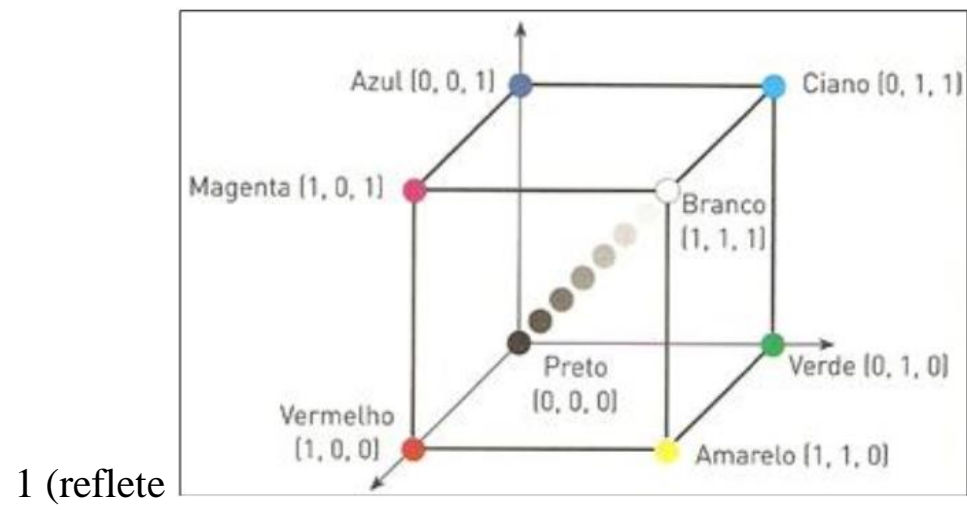
$\square(1,0,0)$ - vermelho
$\square(0,1,0)$ - verde
- $(0,0,1)-$ azul
$\square(1,1,1)$ - branco
- $(0,0,0)$ - preto
$(1,1,0)$ - amarelo
$(0,1,1)$ - ciano
$(1,0,1)$ - magenta muito): 


\section{GERANDO COMPOSIÇÕES COLORIDAS NO ENVI}

A. Selecione a oitava janela vazia no ENVI (ao lado do infravermelho distante 2).

B. Clique em File > Open > selecione o arquivo contém as bandas 1 a 7 do sensor OLI empilhadas.

C. Agora, geraremos composições coloridas. Dessa maneira, vamos associar três diferentes bandas aos três filtros: vermelho, verde e azul. Ao clicar sobre uma primeira banda, verifique que será habilitado o filtro vermelho a ela, na segunda o verde e na terceira azul.

D. Vamos criar uma composição cor verdadeira. Então, clique primeiramente na banda do vermelho e verifique se o botão vermelho acendeu à esquerda. Habilite em seguida o verde e o azul - composição R4/G3/B2 > Load data.

E. Verifique que a imagem será importada para a janela.

F. Crie também uma composição colorida falsa cor na janela 9, que está vazia. Dica: composição composição R5/G4/B6 e diferentes composições.

G. Para alterar a composição colorida utilizada, na caixa Layer maneger, clique com o botão direito do mouse no arquivo > Change RGB bands. 


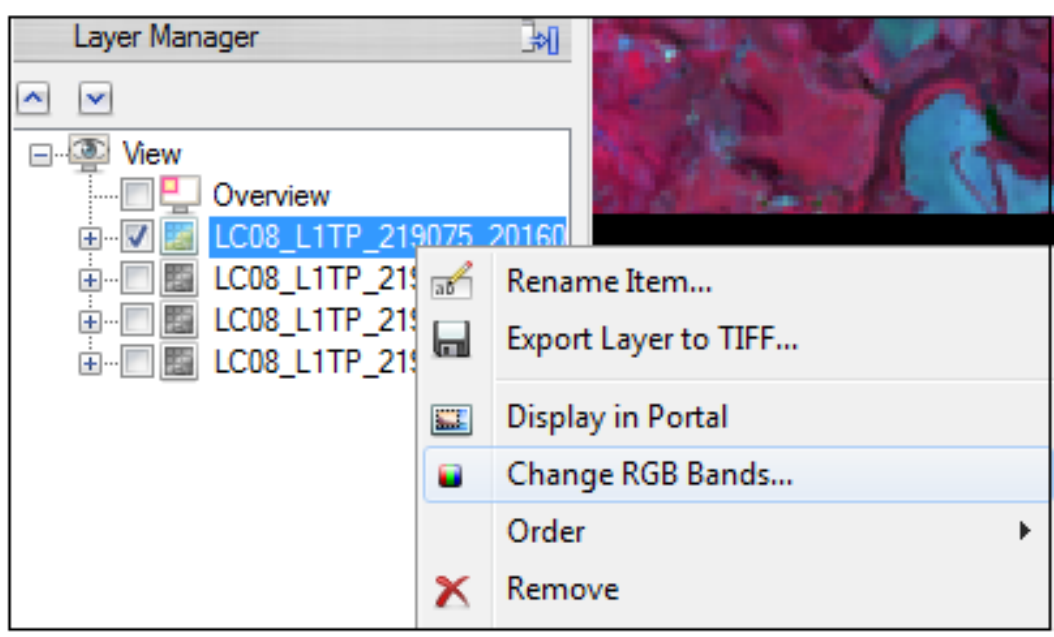




\section{PARTE III}

\section{CONTRASTE DE IMAGENS}

\section{HISTOGRAMA DE IMAGENS}

Um histograma apresenta a distribuição da frequência de pixels nos níveis de cinza (NC) de uma imagem. Quanto mais espalhado for o histograma, maior contraste. Quando menos espalhado, menor o contraste. Na figura abaixo o primeiro histograma representa uma imagem com baixo contraste, enquanto o segundo com alto contraste.

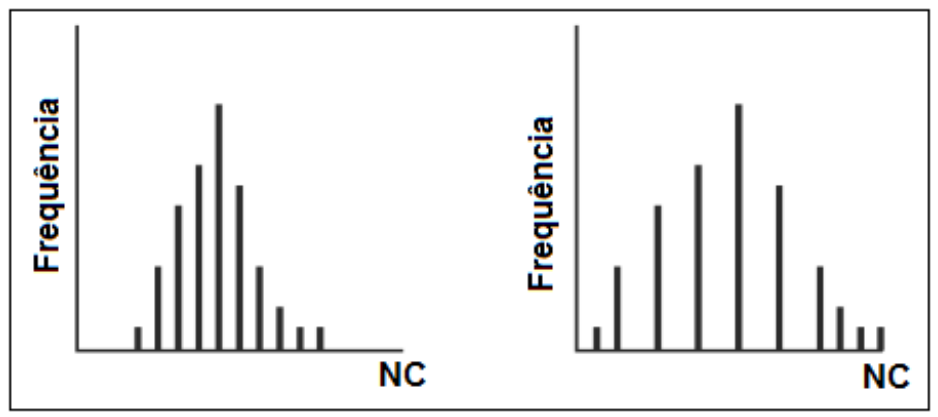

Fonte: Crosta (1992)

Quando o contraste ou qualquer outra função de realce é realizado, o histograma da imagem resultante é diferente do histograma da imagem original. A relação entre os dois histogramas é especificada pela função de transferência de contraste. Essa função é em geral uma curva plotada em relação a dois eixos ( $\mathrm{X}$ e $\mathrm{Y}$ ) representando as intensidades da imagem original e modificada.

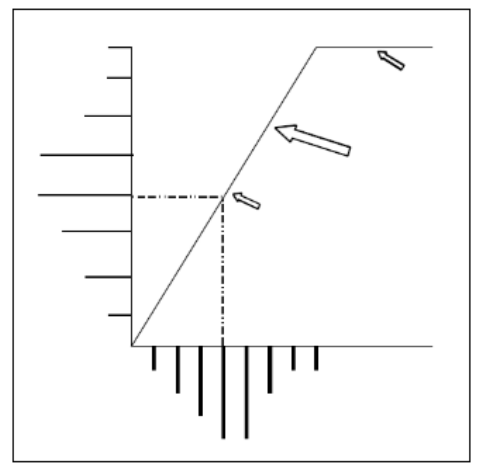

Fonte: Crosta (1992) 


\section{FUNÇÕES DE REALCE DE IMAGENS NO ENVI}

A. Selecione a janela que se deseja fazer uma composição colorida (ex.: composição colorida falsa-cor).

B. O ENVI disponibiliza uma barra com várias ferramentas de realce de imagens:

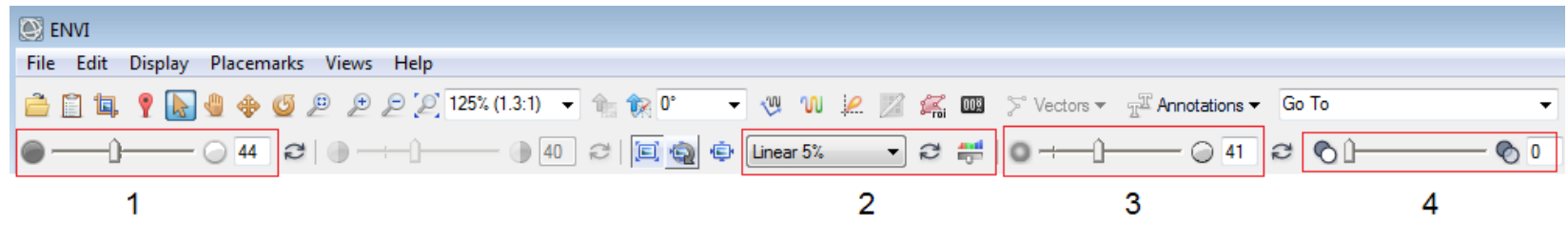

1) Brightness (brilho): relacionado à média dos valores dos pixels. Se a média é próxima de 0 , tem baixo brilho; se é próxima de 255 , alto brilho.

2) Stretch (contraste): relacionado à variância dos valores do pixel. Quanto maior variência, maior contraste. Quanto menor variância, menor contraste.

3) Sharpen: relaciona-se à nitidez da imagem.

4) Transparency: pode-se colocar uma imagem sobre a outra e, colocando transparência na imagem que estiver acima, pode-se visualizar ambas. Quanto mais próximo de 100, maior transparência.

C. Há uma lista de funções de contraste de imagens que podem ser aplicadas (Linear, gaussiano, logarítmico).

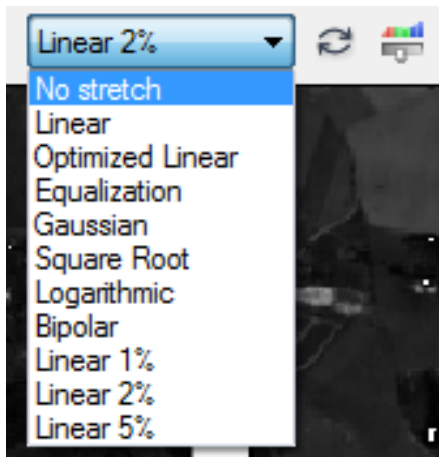




\begin{tabular}{|c|c|}
\hline $\begin{array}{l}\text { XVII Simpósio Brasileiro } \\
\text { de Geografia Fisica Aplicada }\end{array}$ & $\begin{array}{l}\text { OS DESAFIOS DA GEOGRAFIA FÍSICA NA FRONTEIRA DO CONHECIMENTO } \\
\text { Instituto de Geociências - Unicamp }\end{array}$ \\
\hline $\begin{array}{l}\text { I Congresso Nacional } \\
\text { de Geografia Física }\end{array}$ & $\begin{array}{l}\text { Campinas - SP } \\
28 \text { de Junho à } 02 \text { de Julho de } 2017\end{array}$ \\
\hline
\end{tabular}

承 - D. A função Histogram stretch permite visualizar o histograma e manipulá-lo manualmente. 
XVII Simpósio Brasileiro de Geografia Fisica Aplicada

I Congresso Nacional de Geografia Física
OS DESAFIOS DA GEOGRAFIA FÍSICA NA FRONTEIRA DO CONHECIMENTO Instituto de Geociências - Unicamp

Campinas - SP

28 de Junho à 02 de Julho de 2017

\section{Composição falsa cor sem contraste}
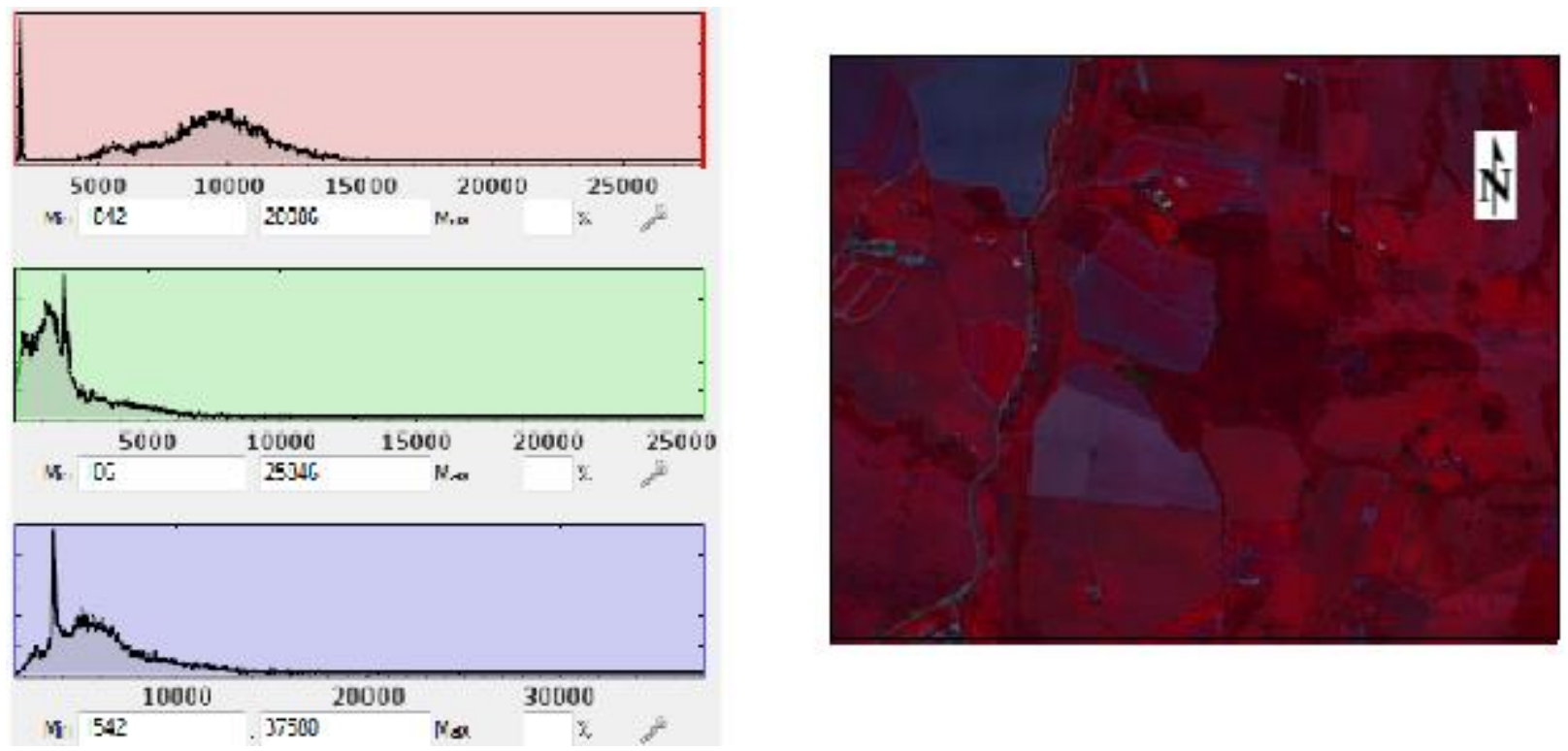

Composição falsa cor com contraste linear 5\%
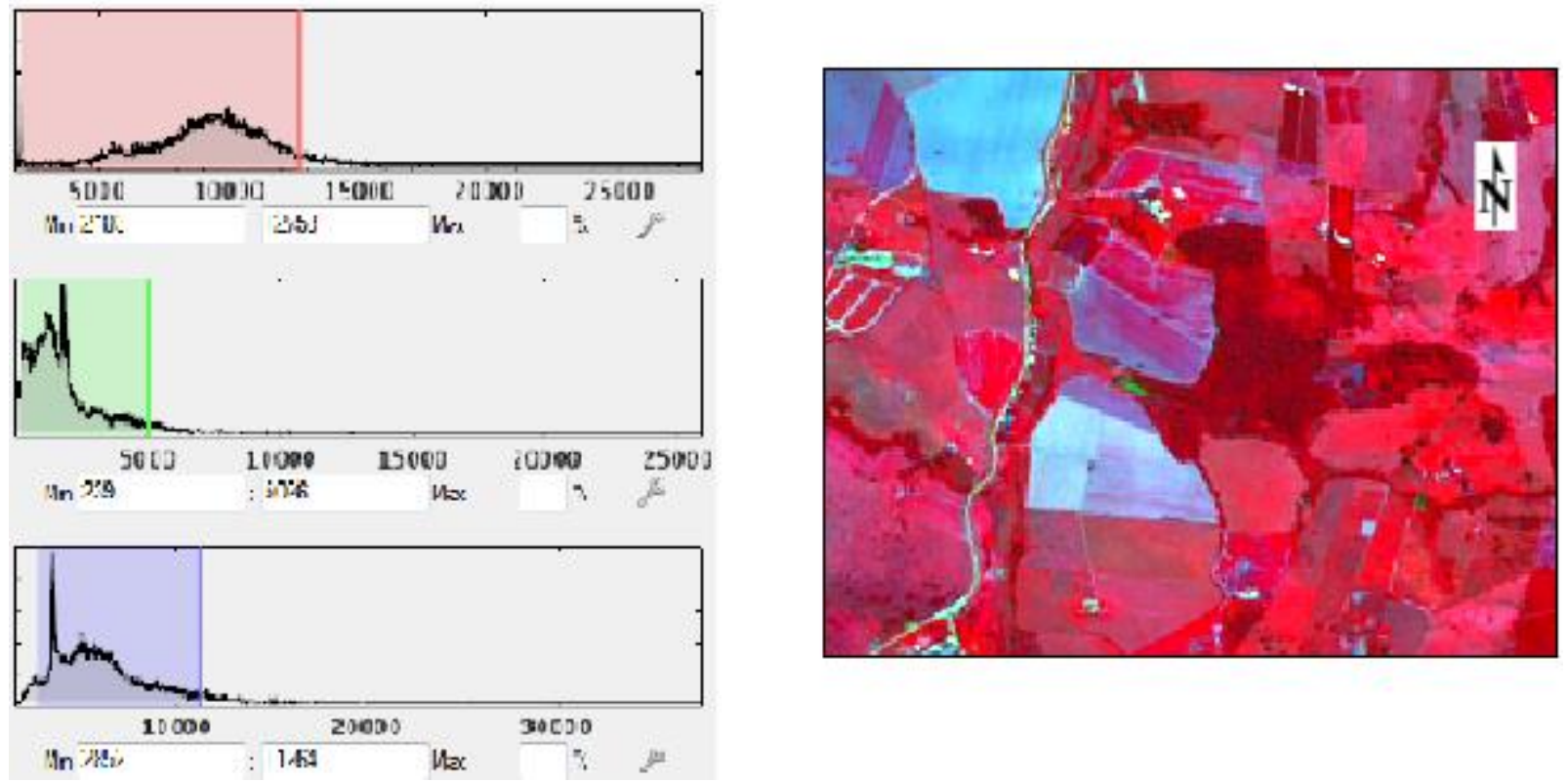


\section{PARTE IV}

\section{GERAÇÃO DE PERFIS ESPECTRAIS E REFLECTÂNCIA DE GEOFÁCIES TERRESTRES}

\section{COMPORTAMENTO ESPECTRAL DO SOLO, VEGETAÇÃO E ÁGUA}

O comportamento espectral, representado pelo perfil espectral ou assinatura espectral, permite-nos diferenciar as geofácies terrestres em imagens multiespectrais. Isso é possível pois em cada banda ou canal, os diferentes alvos refletem a REM em diferentes níveis, o que está associado às suas características. De maneira geral, o comportamento espectral de água, solo e vegetação pode ser representado na figura abaixo.

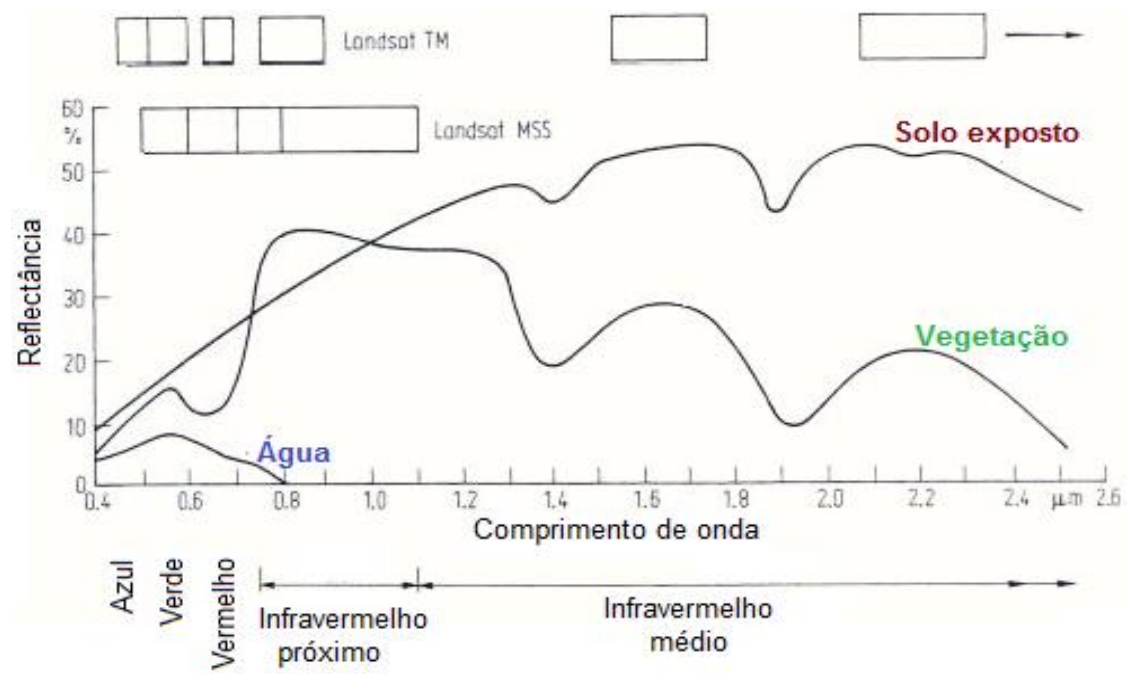

Fonte: adaptado de Gonzales e Woods (1992)

\section{FATORES ASSOCIADOS À REFLECTÂNCIA DOS SOLOS}

A) Umidade: maior umidade causa menor reflectância ao longo do espectro eletromagnético. 
B) Granulometria: percentagem de argila, silte e areia. Quanto menor a partícula, menor a reflectância.

C) Rugosidade superficial: quanto mais grosseira a textura superficial, maior a reflectância.

D) Óxido de ferro: quanto mais óxido de ferro, menor a reflectância.

E) Matéria orgânica: quanto mais matéria orgânica, menor a reflectância (JENSEN, 2009; MOREIRA, 2011).

\section{FATORES ASSOCIADOS À REFLECTÂNCIA DA VEGETAÇÃO}

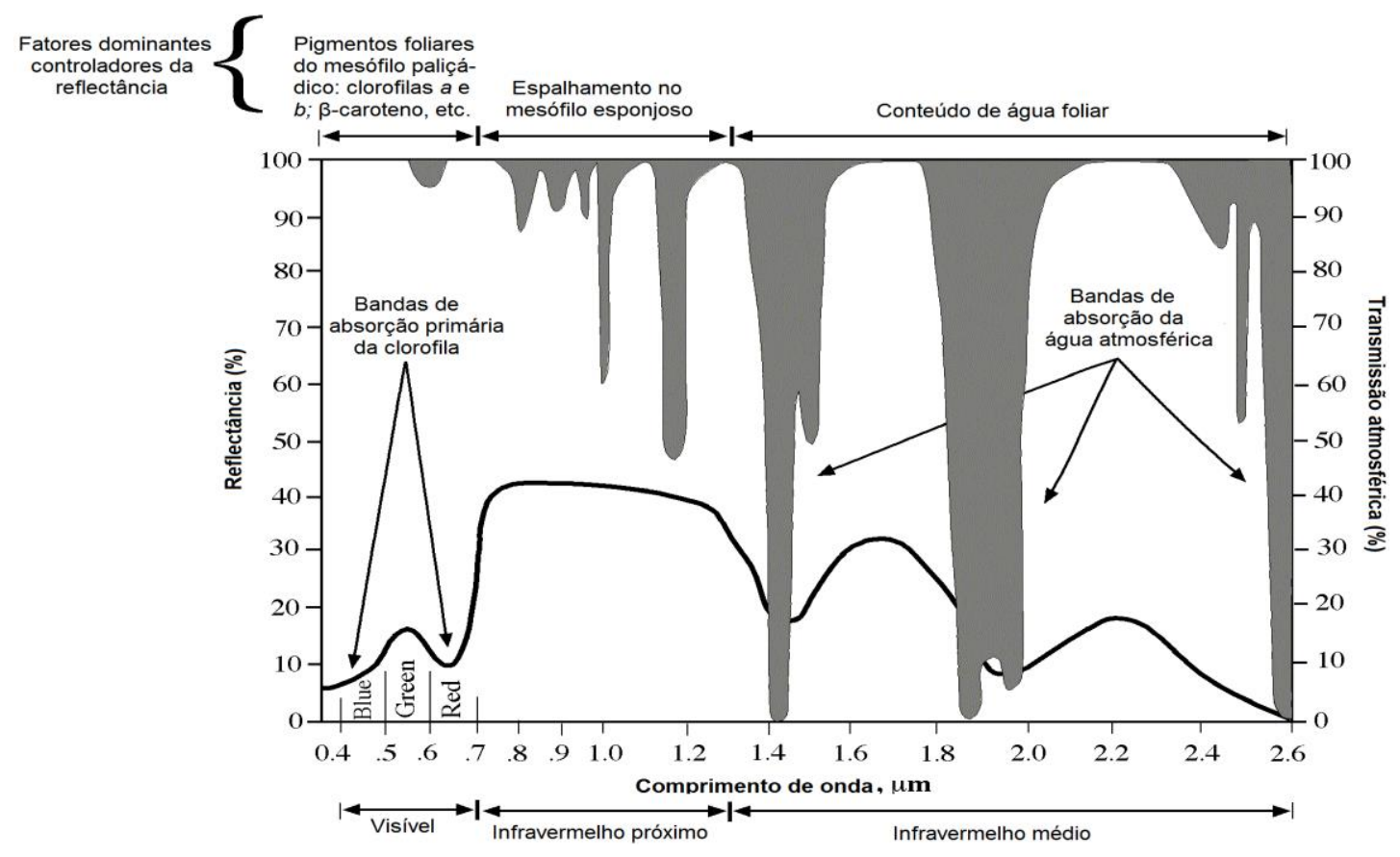

Fonte: Jensen (2009)

\subsection{Fatores associados à reflectância da vegetação no visível}

Na camada superior da folha são encontradas cutículas, as quais exercem papel de proteção. Abaixo são encontradas as células do mesófilo paliçádico, que possuem cloroplastos com pigmentos de clorofila. A clorofila $a$ e clorofila $b$ são os pigmentos mais importantes dos vegetais, absorvedores das luzes vermelha e azul. No entanto, há um decréscimo na absorção no 
verde, o que faz com que a reflectância seja maior nesse canal (JENSEN, 2009; PONZONI et al., 2012).

Nos cloroplastos há também outros pigmentos, como carotenos e xantofilas, que são mascarados pela abundância da clorofila. Se a planta atinge a senescência ou estresse, pode haver redução de clorofila, predominando outros pigmentos. Dessa maneira, a reflectância no verde pode reduzir e aumentar no azul e vermelho (JENSEN, 2009; PONZONI et al., 2012).

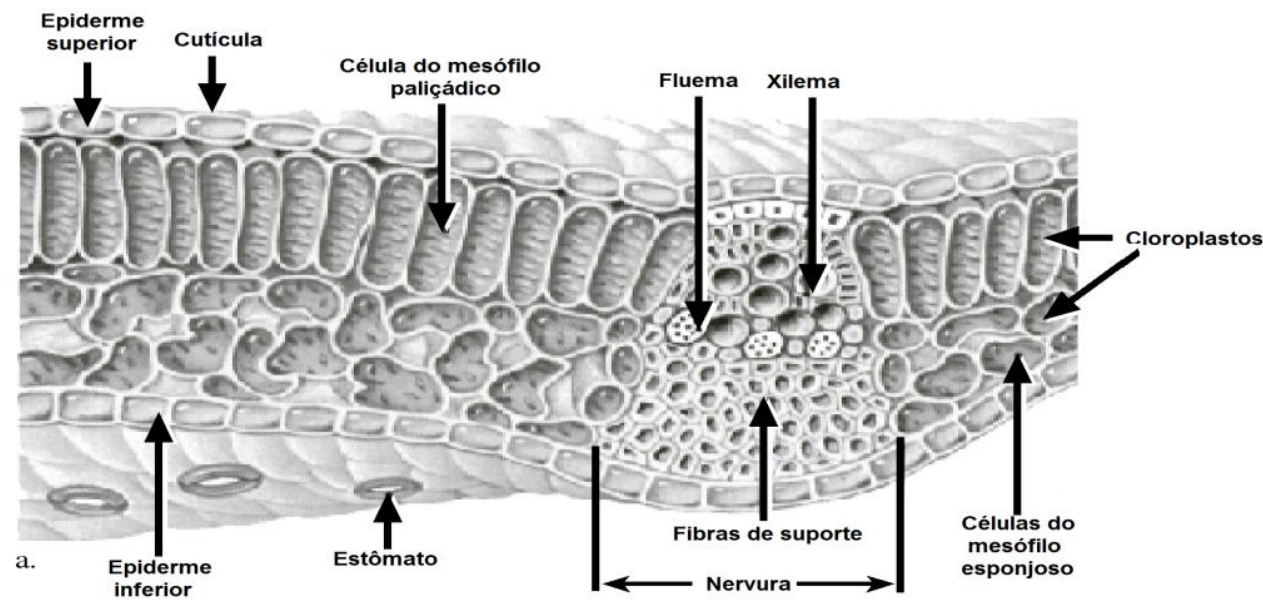

Fonte: Jensen (2009)

\subsection{Fatores associados à reflectância da vegetação no infravermelho próximo}

Numa folha verde, o mesófilo esponjoso controla a quantidade de energia do infravermelho próximo (IVP) que será refletida. (JENSEN, 2009). A folha sadia reflete 40 a 60\% e transmite 45 a 50\% da energia no IVP. Caso a folha absorvesse grande parte da energia do IVP, poderia desnaturalizar (JENSEN, 2009; PONZONI et al., 2012). Dessa maneira, a vegetação tem alta reflectância no IVP.

A reflectância aditiva faz com que a parte da REM transmitida por uma camada superior do dossel para uma camada de inferior seja novamente refletida para a camada superior. Devido à reflectância aditiva, quanto mais denso o dossel da vegetação, maior a reflectância no infravermelho próximo. Por outro lado, se houver folhas esparsas, menor será a reflectância no 


\section{OS DESAFIOS DA GEOGRAFIA FÍSICA NA FRONTEIRA DO CONHECIMENTO \\ Instituto de Geociências - Unicamp \\ Campinas - SP \\ 28 de Junho à 02 de Julho de 2017}

infravermelho próximo. Dessa maneira, há relação direta entre biomassa e a reflectância no infravermelho próximo e inversa no visível (JENSEN, 2009; PONZONI et al., 2012).

\subsection{Fatores associados à reflectância da vegetação no infravermelho médio}

Maior parte da água na folha é armazenada no mesófilo esponjoso. Se ela estiver bem irrigada, ficará completamente túrgida (cheia). Na ausência de irrigação ou chuva, estará em turgidez relativa. A água é um bom absorvedor de energia no infravermelho médio (IVM). Quanto maior turgidez, ou seja, quanto maior umidade na folha, menor a reflectância no IVM. Por outro lado, à medida em que a umidade diminui nas folhas, aumenta a reflectância no IVM (JENSEN, 2009; PONZONI et al., 2012).

\section{FATORES ASSOCIADOS À REFLECTÂNCIA DA ÁGUA}

A água apresenta-se na natureza sob três estados físicos, o que influencia em seu comportamento espectral. Os principais alvos formados pela água são: água líquida, nuvens e neve.

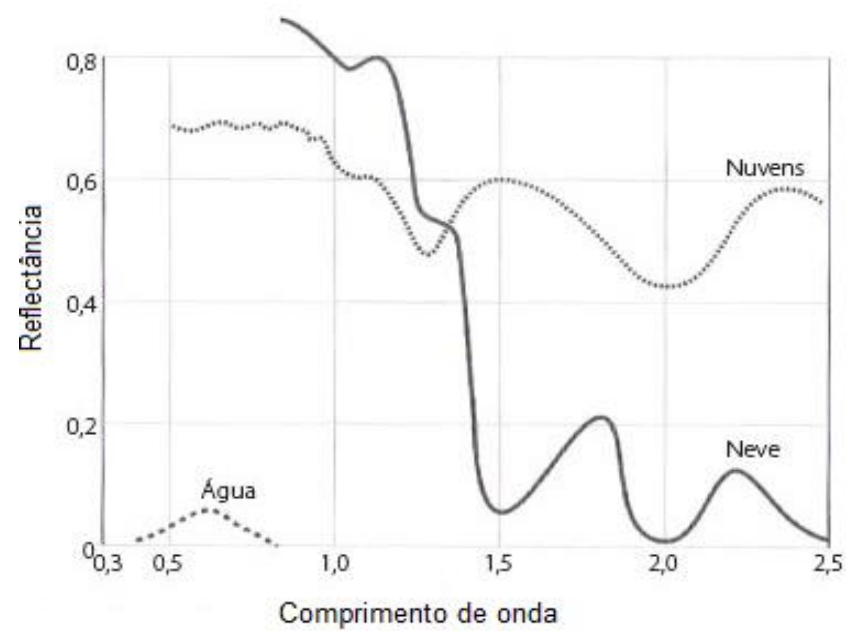

Fonte: Novo (2008)

Diferentes fatores estão associados à reflectância da água líquida, sendo alguns desses fatores: 
A) Concentração sedimentos: quanto maior concentração de sedimentos, maior será a reflectância, com picos nos maiores comprimentos de onda do visível. Quanto maior o tamanho (diâmetro) dos materiais em suspensão, maior a reflectância. Dessa maneira, A reflectância da areia > silte > argila (JENSEN, 2009).

B) Clorifila: no visível há absorção da luz azul pela clorofila a entre 400 e 500nm e absorção da luz vermelha pela clorofila a em $675 \mathrm{~nm}$. Por outro lado, há alta reflectância em 550nm, pela baixa absorção da luz verde pela alga. Há um pico de reflectância próximo do início do infravermelho médio - 700nm.

\section{Geração de perfis espectrais no ENVI}

vv - A. O ENVI permite gerar automaticamente o perfil espectral de pixels na imagem, pelo botão Spectral profile

B. Clique na função spectral profile e selecione uma área na imagem.

C. Em Options > Vegetation index pode-se inserir o valor de índice de vegetação.

D. Pode-se gerar o gráfico inserindo o valor de comprimento de onda ou pelo número da banda na imagem. Basta alterar a unidade desejada para o eixo $X$.

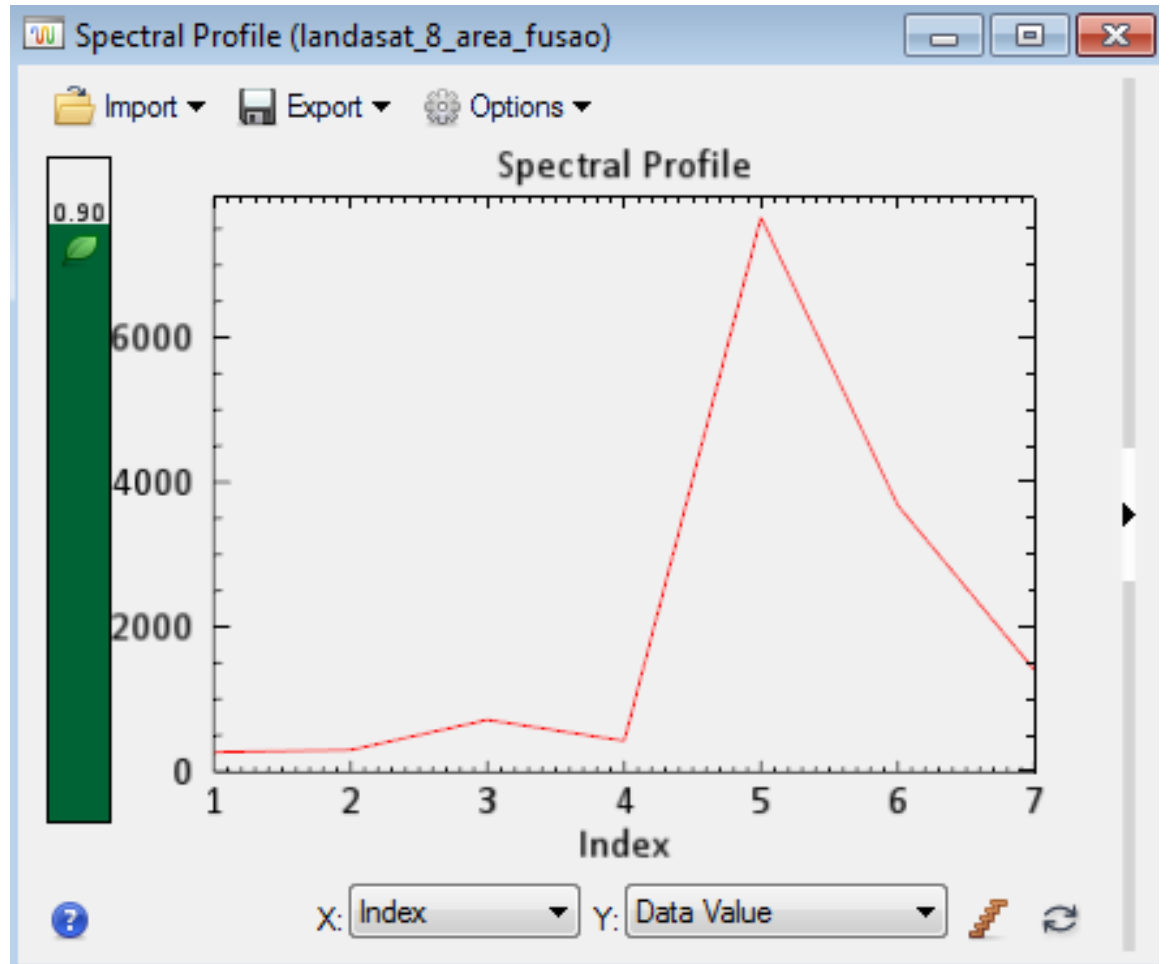




XVII Simpósio Brasileiro
$\begin{gathered}\text { de Geografia Fisica Aplicada } \\ \text { I Congresso Nacional } \\ \text { de Geografia Física }\end{gathered}$

E. Para exportar o gráfico, clique em Export e escolha o formato desejado. 


\section{PARTE V}

\section{CLASSIFICAÇÃO SUPERVISIONADA DE IMAGENS DIGITAIS PIXEL A PIXEL}

\section{O PROCESSO CLASSIFICATÓRIO}

Um dos principais objetivos do Sensoriamento Remoto é distinguir e identificar os diferentes materiais da superfície terrestre (CROSTA, 1992). É possível, através da classificação de imagens, transformar dado em informação, codificando-os em documentos na forma de mapas, gráficos e tabelas (JENSEN, 1996; MENEZES E SANO, 2012). O levantamento da Cobertura e do Uso da Terra indica a distribuição geográfica da tipologia de uso, identificada por meio de padrões homogêneos da cobertura terrestre (IBGE, 2013). O mapeamento de uso do solo pode ser feito através de fotointerpretação ou classificação, como mostra a tabela abaixo:

\begin{tabular}{|l|l|}
\hline \multicolumn{1}{|c|}{ Fotointerpretação } & \multicolumn{1}{c|}{ Classificação } \\
\hline Analista humano & $\begin{array}{l}\text { Baseada em algoritmos de classificação + } \\
\text { análise humana }\end{array}$ \\
\hline Análise feita por regiões & Análise feita pixel a pixel ou por regiões. \\
\hline Limitada a no máximo três faixas espectrais & $\begin{array}{l}\text { Permite analisar simultaneamente inúmeras } \\
\text { faixas espectrais }\end{array}$ \\
\hline $\begin{array}{l}\text { Permite a distinção de um número limitado de } \\
\text { níveis de cinza ou brilho }\end{array}$ & $\begin{array}{l}\text { Permite a distinção de quantos níveis de cinza } \\
\text { houver os dados originais }\end{array}$ \\
\hline
\end{tabular}
Fonte: adaptado de Novo (2010)

O processo classificatório de imagens multiespectrais está associado a várias etapas de processamento digital de imagens, que podem ser divididas em três etapas: pré-processamento, realce e classificação. 


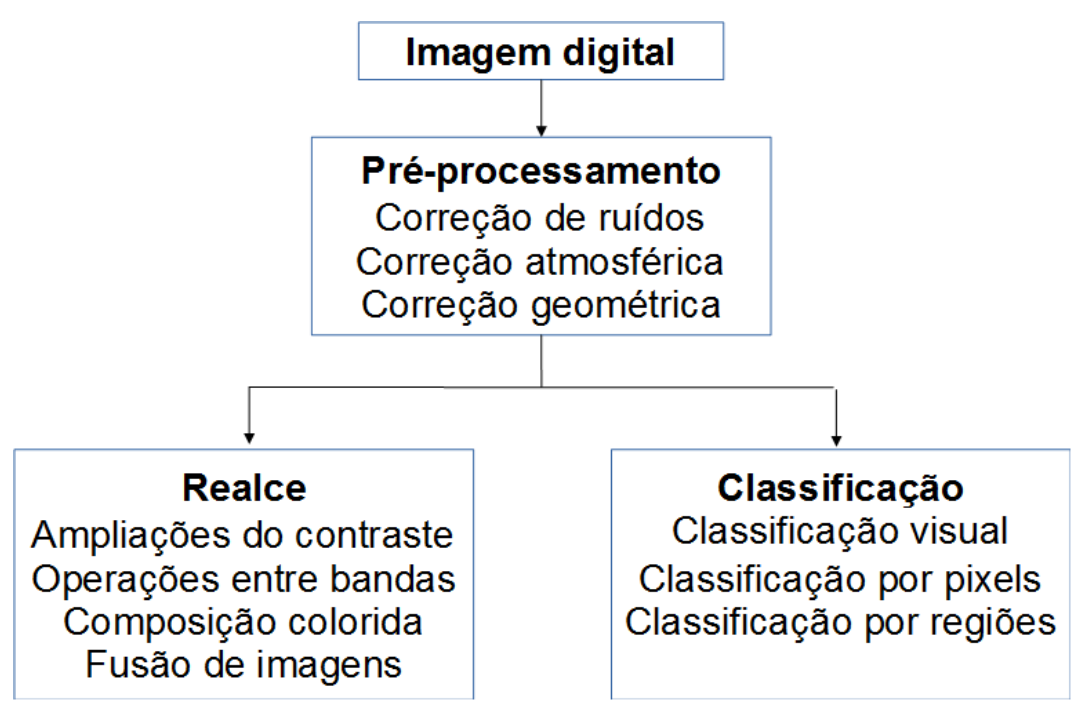

Dessa maneira, antes de iniciar uma classificação devem então ser tomados alguns cuidados na etapa de pré-processamentos para, melhora da acurácia dos resultados. Neste sentido, foi realizada a correção atmosférica pelo método FLAASH. Realizou-se também o empilhamento das multiespectrais - função Layer staking.

A Classificação é o processo que visa atribuir significado a cada pixel ou região de uma imagem, em função de suas propriedades espectrais e espaciais (NOVO, 2010). O processo é realizado utilizando valores de reflectância associada às diferentes bandas espectrais, de diferentes modos, conforme o método ou algoritmo classificador aplicado.

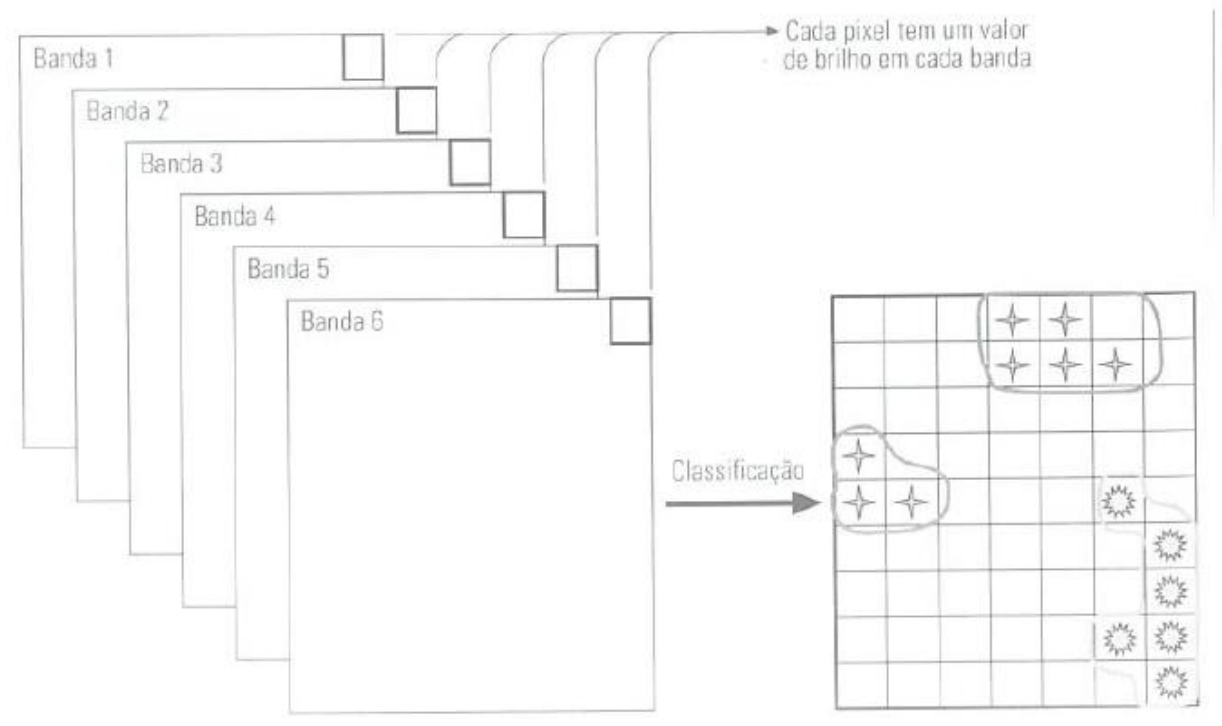


Fonte: Novo (2010)

O conhecimento prévio do analista sobre a área é de fundamental importância, em virtude disto, verificações de campo e entrevistas com moradores locais e inspeções no aplicativo Google Earth Pro ajudam a definir as classes de uso e cobertura do solo. Nesta etapa, dita de campo, deve ser destacada a necessidade de se conhecer o local para melhora da acurácia. Quando há realização de estudos multitemporais, destaca se a importância de entrevista com moradores locais, sobre a configuração pretérita dos usos na paisagem. Estas medidas, visam a redução de erros na interpretação das classes de uso e manejo presentes no estudo.

Devemos destacar a importância de se avaliar o tipo de manejo adotado no uso do solo, pois dependendo do objetivo ele pode ser tão importante quanto o uso. Por exemplo, se formos avaliar a erosão e temos duas áreas distintas, mas com solos e declives iguais, cobertas com milho, do ponto de vista de erosão em função do uso elas teriam a mesma perda de solo. Todavia, uma pode estar plantada utilizando aragem do solo, que resulta na quebra suas estruturas e favorece o escoamento superficial, expondo os solos a ação das intempéries o que leva ao aumentando da erosão e outra, onde o plantio direto é utilizado, este manejo reconhecidamente protege o solo na entre safra e preserva suas estruturas aumentando o teor de matéria orgânica e a umidade nos solos e tem eficiência comprovada na redução da erosão (AYER et al, 2015).

Neste contexto, estaríamos cometendo um erro grosseiro, que acabaria por aumentar a perda de solo caso você fosse aplicar a Equação Universal de Perda de Solo por exemplo. Dessa forma, o conhecimento dos manejos aplicadas na área, podem ser fundamental, dependendo do seu objetivo, por isto, o reconhecimento prévio da área e ou entrevistas com moradores pode melhorar a acurácia dos resultados (AYER et al, 2015).

\section{CLASSIFICAÇÃO SUPERVISIONADA}

A classificação supervisionada está baseada no conhecimento prévio das classes de uso do solo, em uma cena ou recorte da imagem. O algoritmo precisa ser treinado pelo analista para 


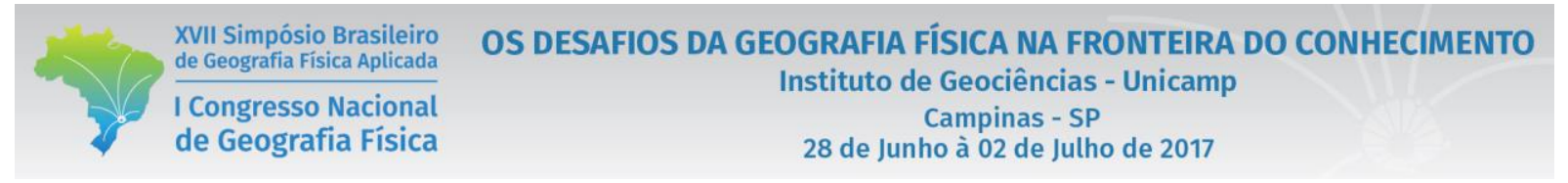

distinguir as diferentes classes. Para isso, o usuário deve identificar amostras das classes de uso na imagem, chamadas de áreas ou amostras de treinamento, como mostra o exemplo abaixo.

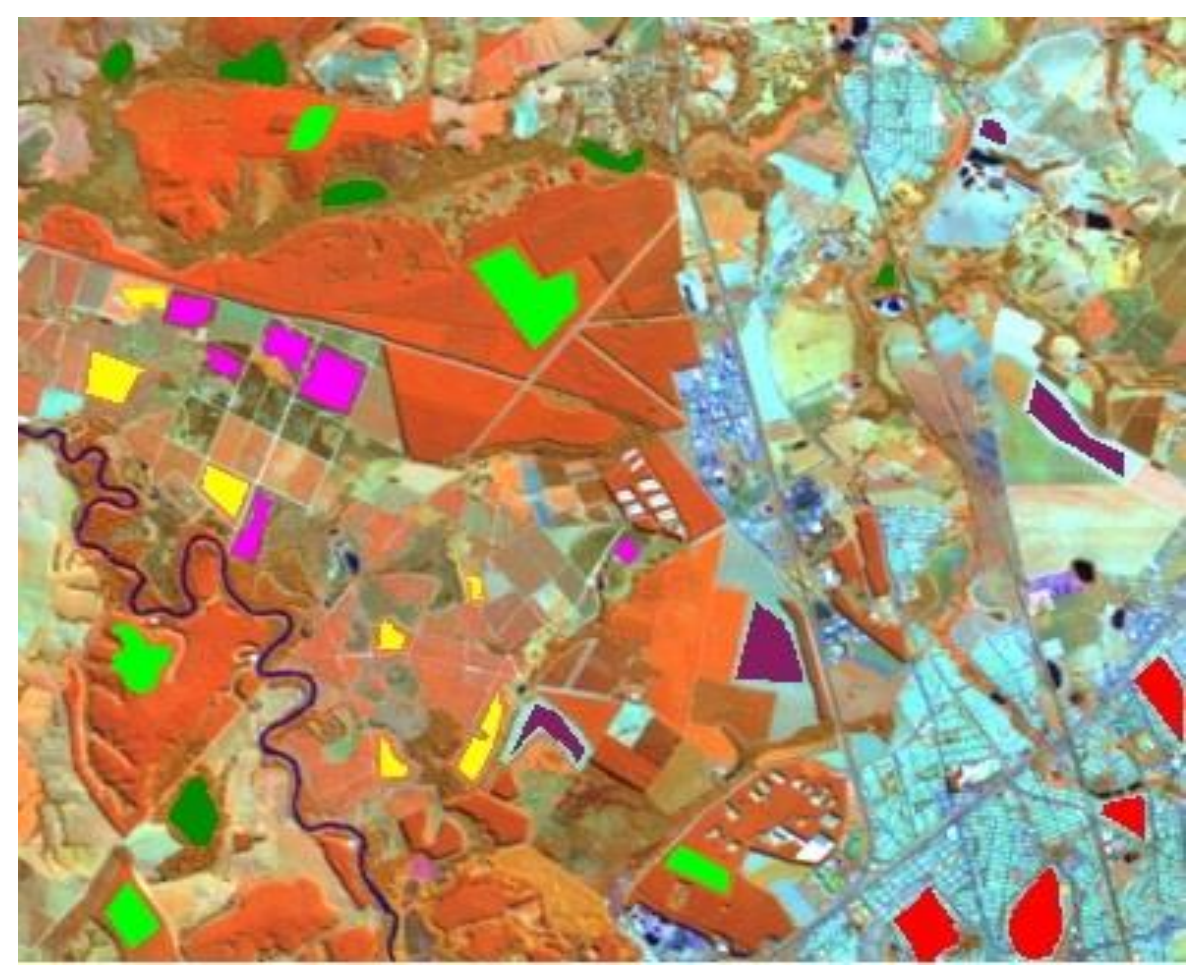

Para gerar amostras de treinamento, clique na função Region of interest (ROI) tool. Devem ser geradas amostras dos seguintes usos do solo:
1. Mata
2. Eucalipto
3. Agricultura (culturas temporárias)
4. Café
5. Pastagem
6. Água 


\begin{tabular}{|c|c|}
\hline $\begin{array}{l}\text { XVII Simpósio Brasileiro } \\
\text { de Geografia Fisica Aplicada }\end{array}$ & $\begin{array}{l}\text { OS DESAFIOS DA GEOGRAFIA FÍSICA NA FRONTEIRA DO CONHECIMENTO } \\
\text { Instituto de Geociências - Unicamp }\end{array}$ \\
\hline $\begin{array}{l}\text { I Congresso Nacional } \\
\text { de Geografia Física }\end{array}$ & $\begin{array}{c}\text { Campinas - SP } \\
28 \text { de Junho à } 02 \text { de Julho de } 2017\end{array}$ \\
\hline
\end{tabular}

7. Urbano

8. Solo úmido

9. Solo menos úmido 
XVII Simpósio Brasileiro de Geografia Fisica Aplicada

I Congresso Nacional de Geografia Física
OS DESAFIOS DA GEOGRAFIA FÍSICA NA FRONTEIRA DO CONHECIMENTO

Instituto de Geociências - Unicamp

Campinas - SP

28 de Junho à 02 de Julho de 2017

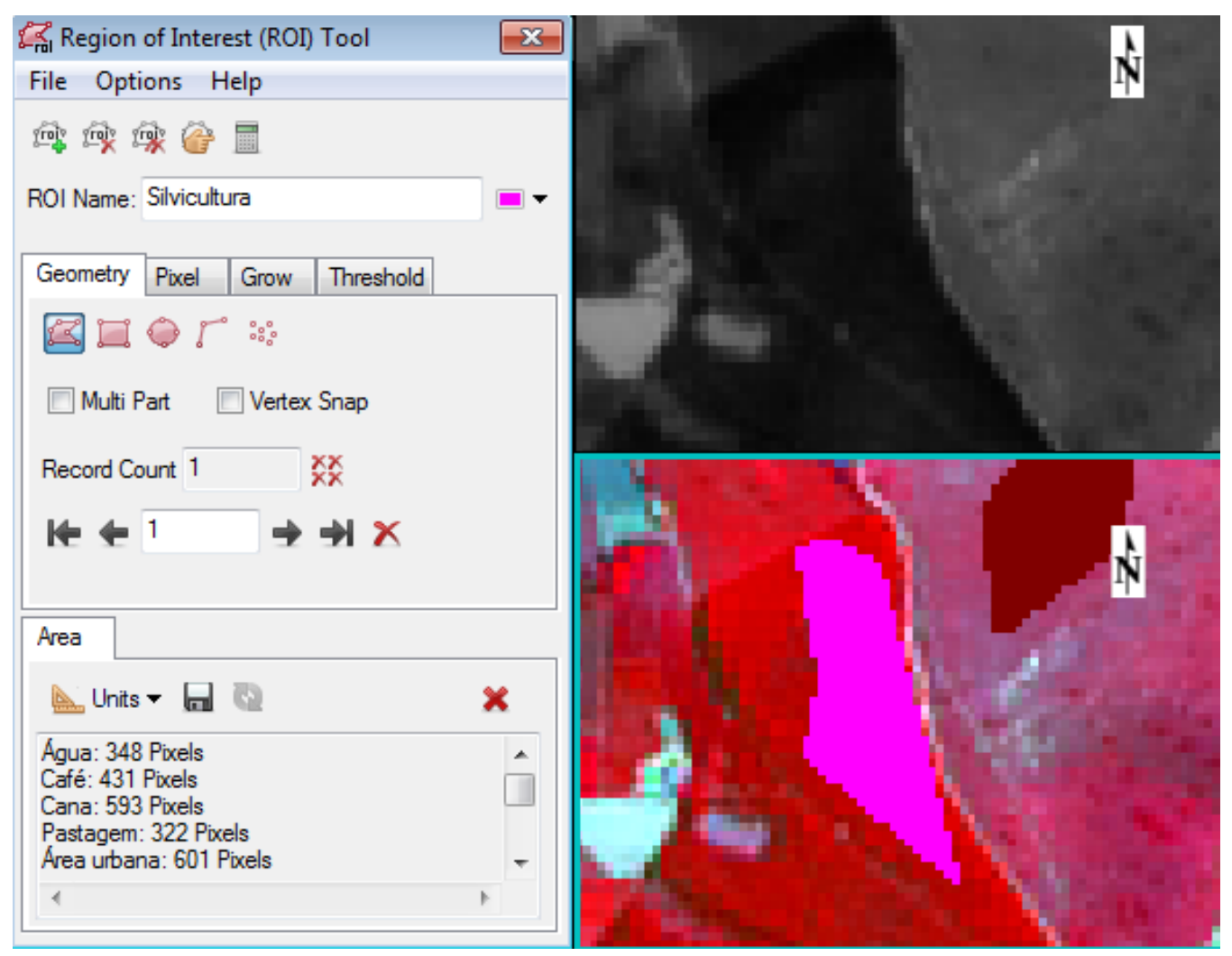

Algumas funções importantes para a geração de ROIs são:

1. New ROI: utilizada para gerar um novo ROI.

2. Remove ROI: deleta o ROI que está habilitado.

3. Remove all ROIs: deleta todos os ROIs criados (todas as classes).

4. Select next ROI: utilizado para selecionar o ROI que se deseja habilitar.

5. Compute statics: apresenta as estatísticas associadas à reflectância dos pixels em todas as bandas utilizadas.

\section{CLASSIFICAÇÃO PELO ALGORITMO DISTÂNCIA MÍNIMA}

O método mínima distância aloca os pixels da imagem de acordo com a média das amostras de treinamento (centro médio da classe) (MENEZES E SANO, 2012). O pixel será agrupado em uma classe através da medida de similaridade euclidiana, dada por:

$$
D(x, n)=\sqrt{\left(x_{i}-m_{i}\right)^{2}}
$$


onde: $\mathrm{xi}=$ pixel candidato; $\mathrm{mi}=$ média das classes; $\mathrm{n}=$ número de bandas .

O pixel é alocado para a classe de maior similaridade euclidiana (menor distância euclidiana -D). Imagine um pixel que contém $40 \%$ de mata e $60 \%$ de solo exposto, ou seja, que há mistura espectral. Onde este pixel deveria ser alocado? Onde houver maior similaridade euclidiana (menor distância euclidiana).

Uma vantagem do método é que não haverá pixels não classificados (como no caso do método Paraleletpípedo). Os pixels sempre encontrarão uma média a qual estarão mais próximos. O método não considera a variabilidade espacial. Em classes de alta variabilidade, como por exemplo áreas urbanas, incluem-se pixels que tendem a ser distantes da média da assinatura da classe. Esses pixels poderão ser classificados em outras classes.

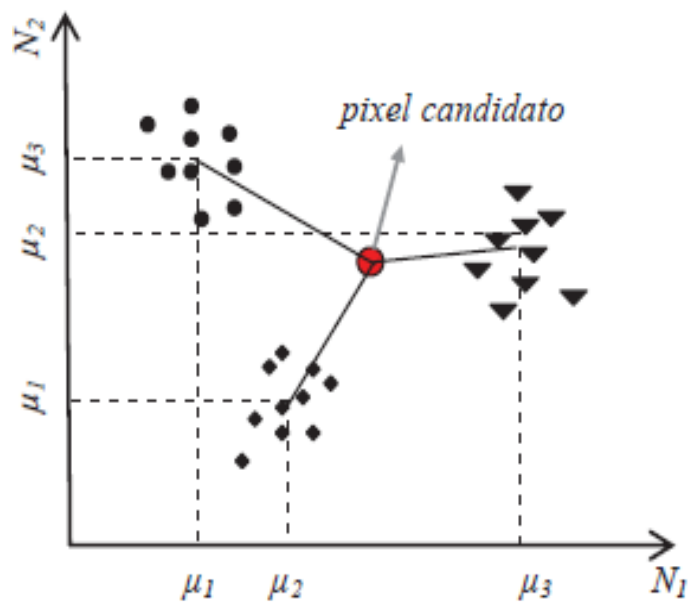

Fonte: adaptado de Menezes e Sano (2012)

\begin{abstract}
A. Para realizar a classificação pelo algoritmo Mínima distância, no Toolbox clique em Classification > Supervisioned classification > Minimum distance > Minimum distance classificarion.
\end{abstract}

B. Na janela Classification input file selecione o arquivo que contém as sete bandas empilhadas > $O K$.

C. Na janela Minimum distance parameters selecione as nove amostras de classes de uso que serão utilizadas (amostras de treinamento). 
D. Indique o local em que se deseja salvar a imagem e clique $O K$ para gerar a classificação.

\section{CLASSIFICAÇÃO PELO ALGORITMO MÁXIMA VEROSSIMILHANÇA}

Um dos métodos mais comuns e complexos é o máxima verossimilhança (em Inglês, maximum likelihood) ou simplesmente MaxVer, que utiliza parâmetros estatísticos no processo classificatório. Esse algoritmo supõe que a distribuição da nuvem de pontos das amostras de treinamento apresentam distribuição normal. Dessa maneira, utilizam-se parâmetros como média e desvio padrão para identificarem as classes dos pixels espalhados pela imagem (LILLESAND et al., 2008).

A função densidade de probabilidades, em forma de elipses, são utilizadas para classificar pixels não identificados. Portanto, nessa classificação, cada pixel é destinado à classe que tem a maior probabilidade de pertencimento, ou seja, a máxima verossimilhança (LILLESAND et al., 2008).

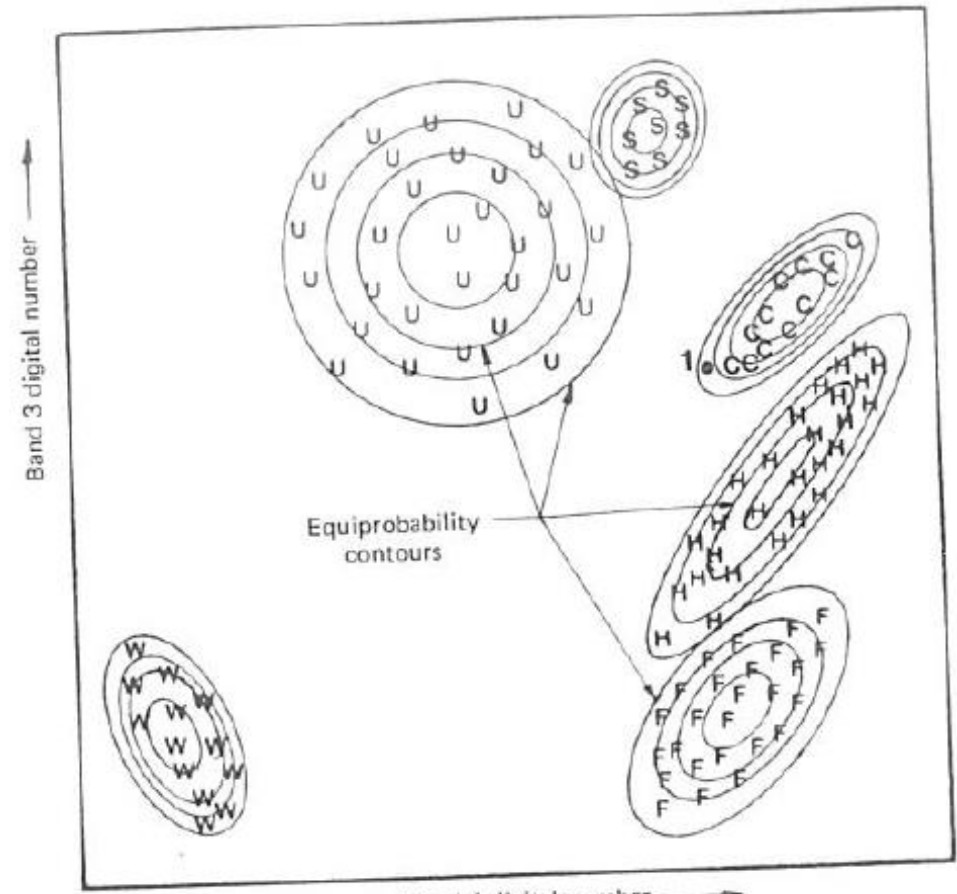

Band 4 digital number $\longrightarrow$

Fonte: Lillesand et al. (2008) 
A. Para realizar a classificação pelo algoritmo Mínima distância, no Toolbox clique em Classification > Supervisioned classification > Minimum distance > Maximum likelihood classificarion.

B. Na janela Classification input file selecione o arquivo que contém as sete bandas empilhadas > $O K$.

C. Na janela Minimum distance parameters selecione as nove amostras de classes de uso que serão utilizadas (amostras de treinamento).

D. Indique o local em que se deseja salvar a imagem e clique $O K$ para gerar a classificação. 


\section{PARTE VI}

\section{CLASSIFICAÇÃO SUPERVISIONADA ORIENTADA A OBJETO}

\section{O PROCESSO CLASSIFICATÓRIO ORIENTADO A OBJETO}

Os métodos de classificação de imagens discutidos até agora são baseados nas características espectrais dos pixels. Contudo, a classificação por regiões utiliza padrões espaciais e espectrais na classificação de imagens (LILLESAND et al., 2008).

A. Para iniciar a classificação orientada a objeto, abra o Envi 5.0, navegue até caixa onde estão localizadas as toolboxs do ENVI > abra o modulo feature extraction.

B. Navegue até à pasta Feature extraction, expanda a mesma e clique na função Example Based Feature Extraction Workflow.

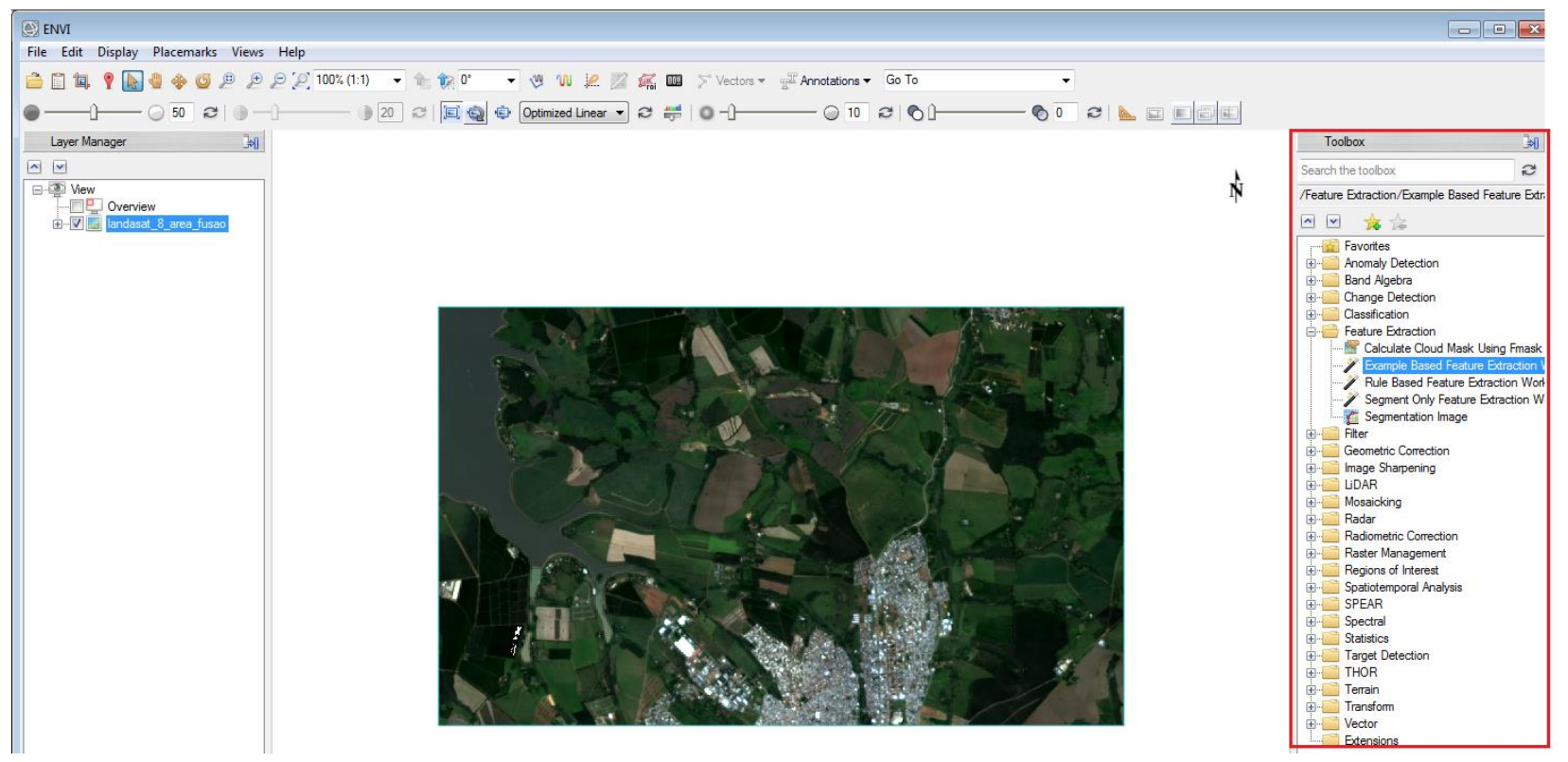


C. Será aberta a janela do Data selection, nesta etapa deverá ser aberto o arquivo Landsat_8_area_fusao (que contém as bandas empilhadas), para isto clique em Browse e direcione o local onde está o arquivo.

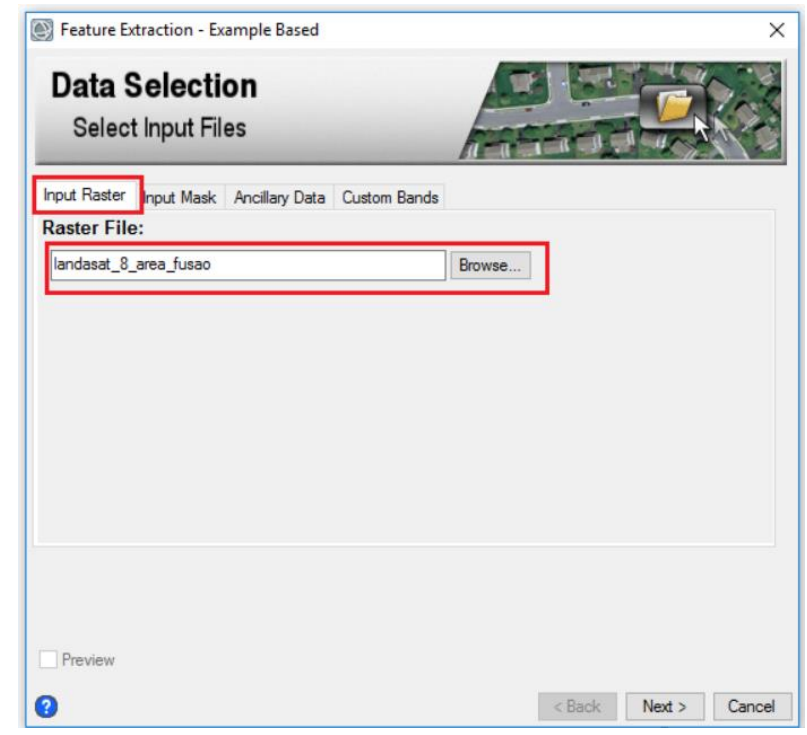

D. Na aba Input Mask é possível adicionar mascaras para recortar a imagem. $\mathrm{Na}$ aba Custom Bands, deixe selecionado a opção Normalized Difference que irá criar o NDVI da área, para servir como base aos testes de classificação, defina as bandas para visualização durante a segmentação na próxima etapa. Nós optamos pela falsa cor R5G4B3. 


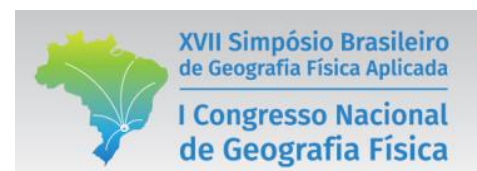

OS DESAFIOS DA GEOGRAFIA FÍSICA NA FRONTEIRA DO CONHECIMENTO

Instituto de Geociências - Unicamp

Campinas - SP

28 de Junho à 02 de Julho de 2017
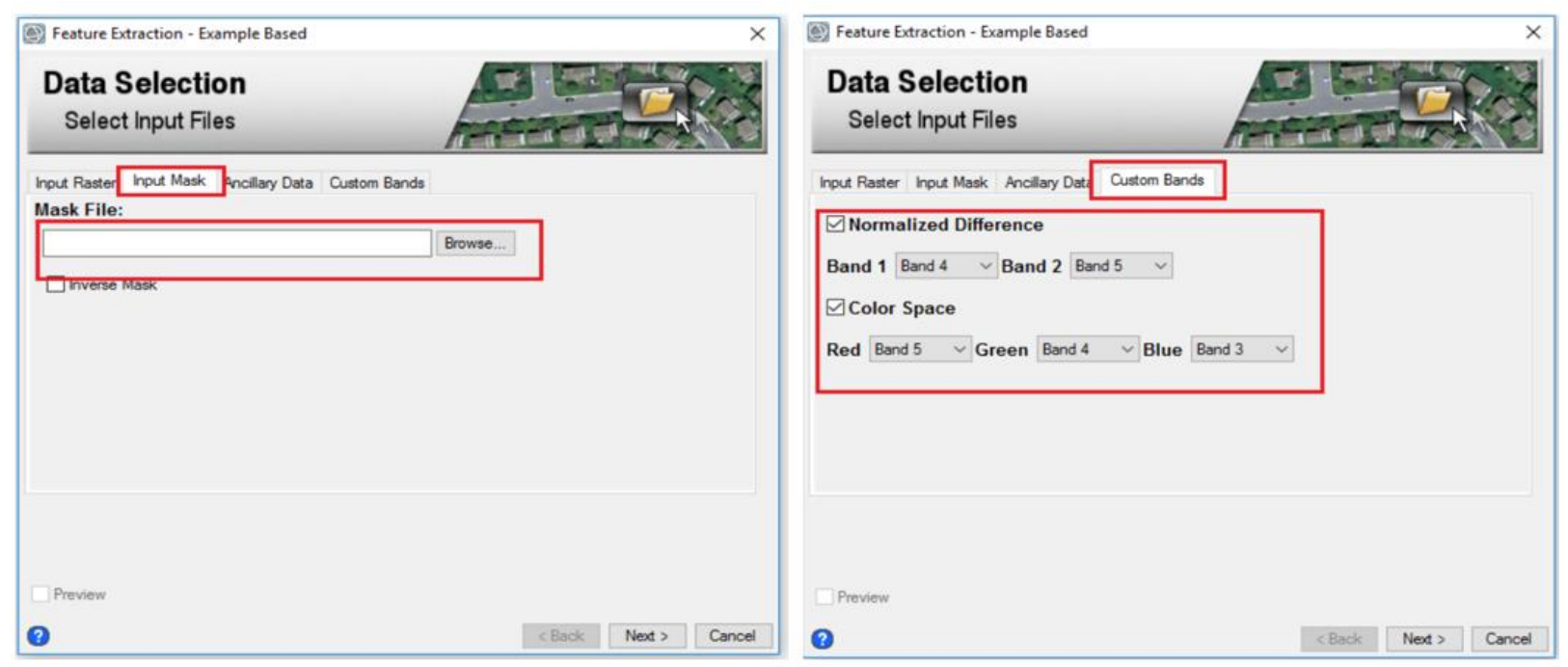

E. É importante destacar, que as composições falsas cores, que utilizam as bandas do infravermelho, facilitam a discriminação de classes com comportamento espectral semelhante, quando comparadas a cor verdadeira RGB, como por exemplo solo exposto e solo preparado para plantio, o que pode ajudar a melhorar a acurácia do mapeamento. Em virtude disto, a escolha das bandas deve ser feita em função dos objetivos propostos, atentando, para o comportamento espectral dos alvos que devem ser classificados.

F. Para dar continuidade ao processo de classificação, clique em avançar (Next), e será aberta a aba do Object Creation - Segment and Merge, aqui serão definidos limiares de segmentação e agrupamento. Para isto, serão necessários estabelecer dois parâmetros para segmentação da imagem como demonstra figura abaixo. 

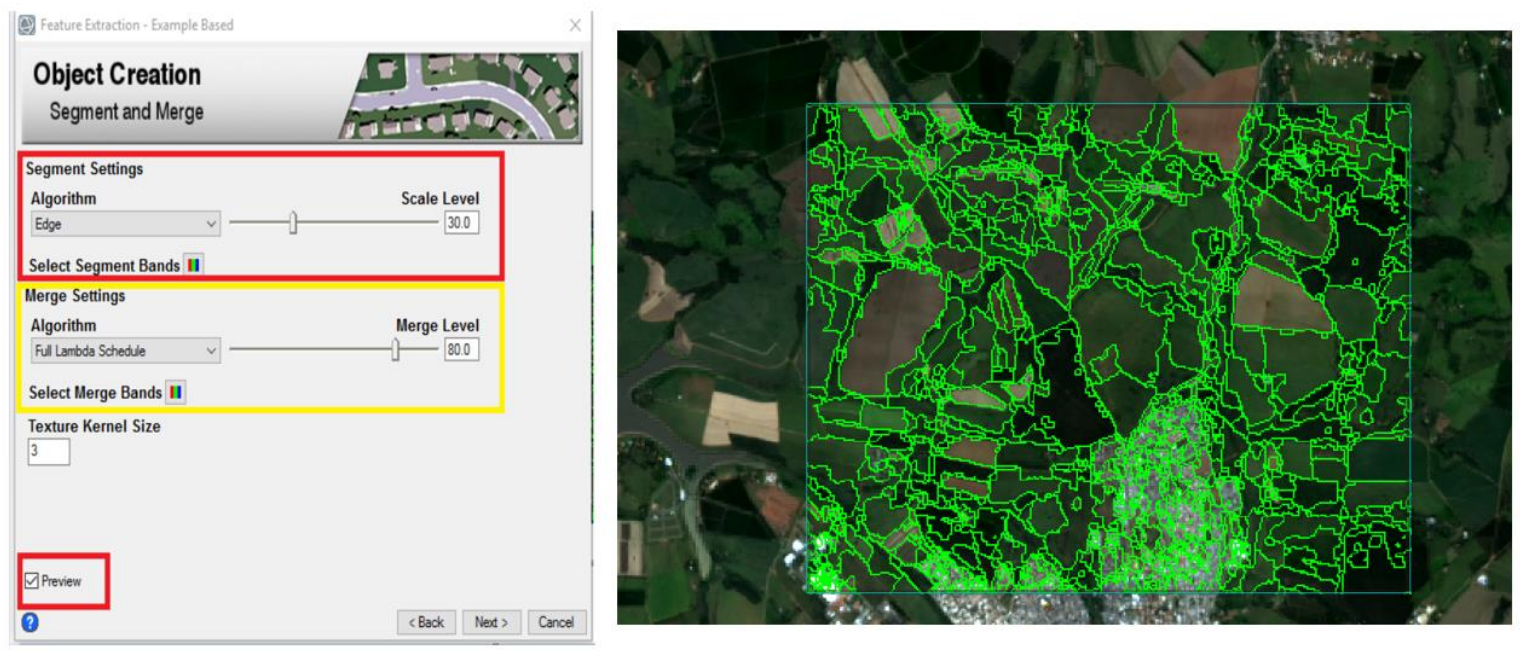

G. O agrupamento dos pixels é determinado pelo nível de escala, variável de 1 a 100 , que determina a densidade da segmentação. Foi utilizado também o parâmetro nível de agregação, usado para unir pequenos segmentos em áreas maiores (ENVI, 2016). O nível de agregação também varia de 1 a 100 e segue o algoritmo de Robinson, Redding e Crisp (2002), que funde segmentos adjacentes com base na combinação de informação espectral e espacial.

H. A partir deste arquivo, numa composição falsa cor (R5G4B6) com contraste linear de 2\%, foram definidos os valores 30 para o limiar do nível de escala (Segment Settings) e 80 para o limiar do nível de agregação (Merge Settings), sendo gerado um arquivo segmentado. A definição destes limiares deve ser tratada com a devida atenção, visto que estes segmentos serão a base para a próxima etapa que irá classificar os segmentos a partir de atributos não paramétricos. Deixe o default no item Texture Kernel Size e marque a opção Preview, que permite a visualização da segmentação gerada.

I. Teste diferentes valores para os parâmetros Segment e Merge até obter uma segmentação que atenda suas demandas. Finalizado clique em avançar (next), irá ser aberta a janela Example-Based Classification - Choose Examples como na figura abaixo. Nesta janela, serão estabelecidas as classes que irão ser geradas (example selection); definidos quais atributos serão utilizados para a classificação (Atribute selection); e qual algoritmo será empregado na classificação (Algorithms). 

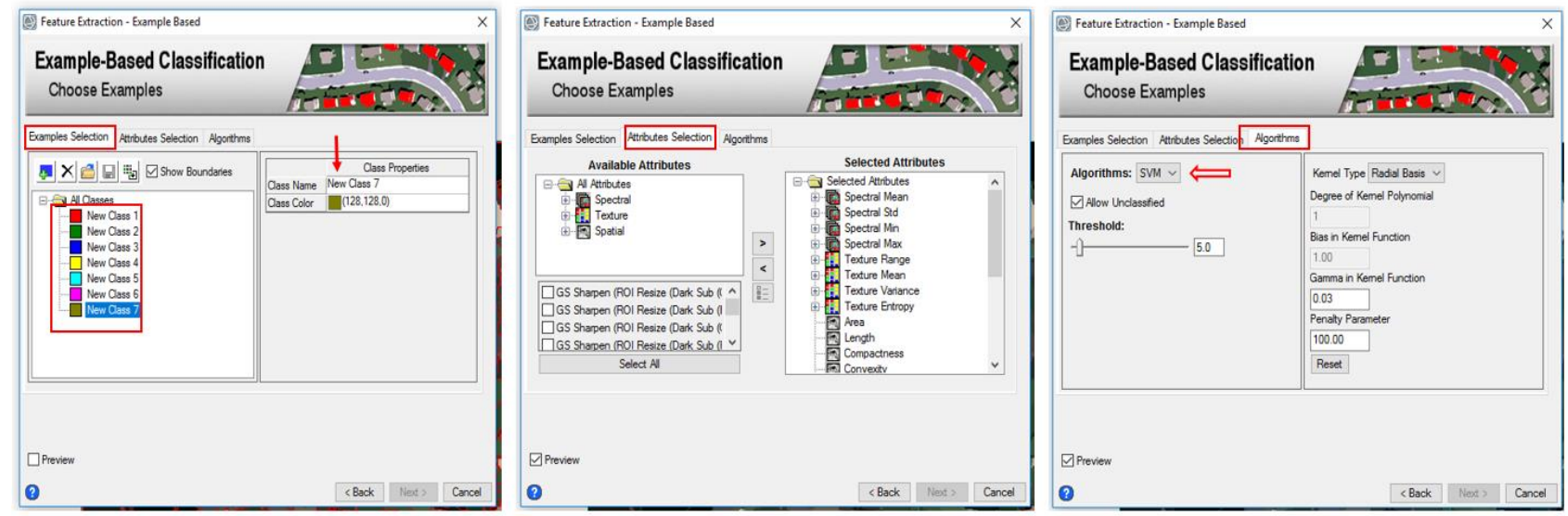

J. Na guia Examples selection, serão inseridas quais as classes presentes no mapeamento. Nesta etapa, serão colhidas amostras para cada classe criada, destas serão extraídas as informações não paramétricas, para que o algoritmo possa realizar a classificação supervisionada orientado a objeto, a partir dos segmentos da imagem gerados na etapa anterior.

K. Desse arquivo, sobreposto à composição R5G4B6, devem ser extraídos, visualmente, em média 20 segmentos para cada classe de uso, utilizados como dados de treinamento para interpretação das classes pelos algoritmos. A seleção dos segmentos deve ser sustentada pela análise visual das imagens, levantamentos de campo e entrevistas informais com moradores locais. Para melhora dos resultados, não esquecer de coletar amostras bem distribuídas e em polígonos de tamanhos variados, sobre a imagem, como demonstra a figura abaixo. 

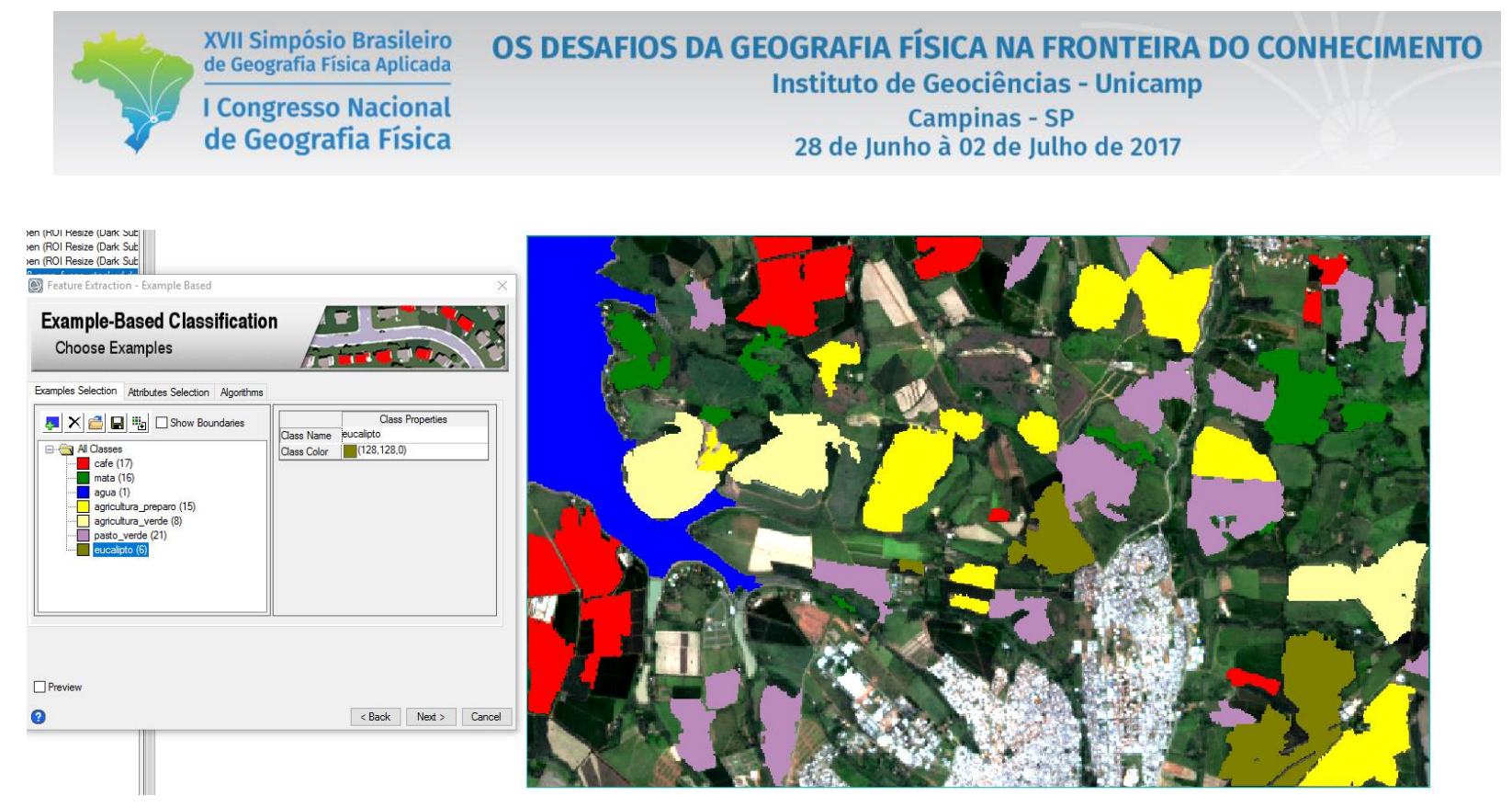

L. Na aba Atributtes selection, deve se escolher quais atributos serão usados para classificar suas amostras de treinamento. Clique na guia Seleção de atributos para ver as opções disponíveis. Por padrão, todos os atributos serão usados para classificação. Esses atributos podem ser descritos como:

1. Atributos Espectrais: Os atributos espectrais são calculados em cada banda da imagem de entrada. O valor do atributo para um segmento específico é calculado a partir da banda de dados de entrada onde a imagem do rótulo de segmentação tem o mesmo valor (ou seja, todos os pixels no mesmo segmento contribuem para o cálculo do atributo) (HARRIS GEOSPATIAL, 2017).

2. Atributos de textura: Os atributos de textura são calculados em cada banda da imagem de entrada. A computação de atributo de textura é um processo de duas etapas onde a primeira passagem aplica um núcleo quadrado de tamanho pré-definido à banda de imagem de entrada. Os atributos são calculados para todos os pixels na janela do kernel e o resultado é referenciado ao pixel central do kernel. Em seguida, os resultados do atributo são calculados em média em cada pixel no segmento para criar o valor do atributo para o rótulo de segmentação dessa banda (HARRIS GEOSPATIAL, 2017) 
3. Atributos espaciais: Os atributos espaciais são calculados a partir do polígono que define o limite do segmento, de modo que a informação da banda não é necessária (HARRIS GEOSPATIAL, 2017)

M. Após a definição dos atributos que serão utilizados para classificar as amostras de treinamento, clique na guia Algorithms e selecione um método na lista, para realizar a classificação supervisionada KNM, PCA, SVM, descritos abaixo:

1. KNN: este método classifica os segmentos com base na sua proximidade com regiões de treinamento vizinhas. O método KNN é mais lento em comparação com o PCA, particularmente quando sua imagem de segmentação possui milhares de segmentos. No entanto, é um método mais rigoroso que distingue mais precisamente entre classes semelhantes. Você só precisa definir uma classe para prosseguir com a classificação KNN (HARRIS GEOSPATIAL, 2017).

2. PCA: este método atribui segmentos a classes usando uma análise de componentes principais. Você deve definir pelo menos duas classes com um mínimo de duas regiões de treinamento cada (HARRIS GEOSPATIAL, 2017).

3. SVM: Este é o mais rigoroso dos três métodos de classificação, então o tempo de processamento será mais lento. Cada classe deve ter pelo menos duas amostras de treinamento; caso contrário, a classe será excluída da classificação (HARRIS GEOSPATIAL, 2017).

N. Para a execução desse curso, escolhemos o algoritmo SVM (Support Vector Machine) que é considerado mais robusto para os objetivos desejados. utilize o default para os parâmetros do $S V M$.

O. Depois de definidas as classes e parâmetros clique em next, será aberta a janela export - Save results. Nas abas export vector e export raster, habilite para exportar o arquivo da classificação orientado a objeto nos formatos desejados como demonstra a figura abaixo. $\mathrm{O}$ layout pode ser 


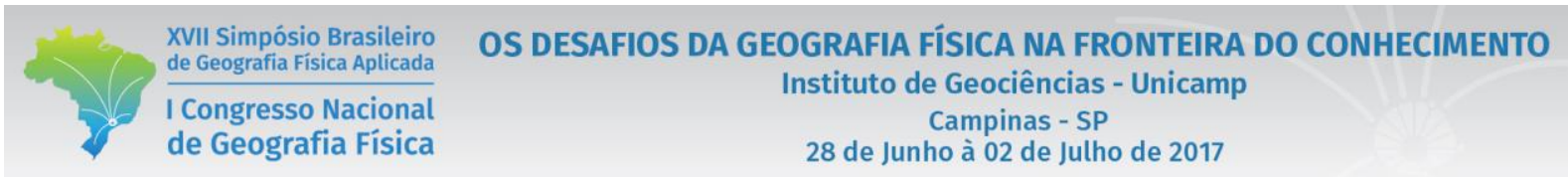

feito no próprio ENVI ou os arquivos podem ser exportado para o ArcGIS ou outro software desejado, para sua finalização.
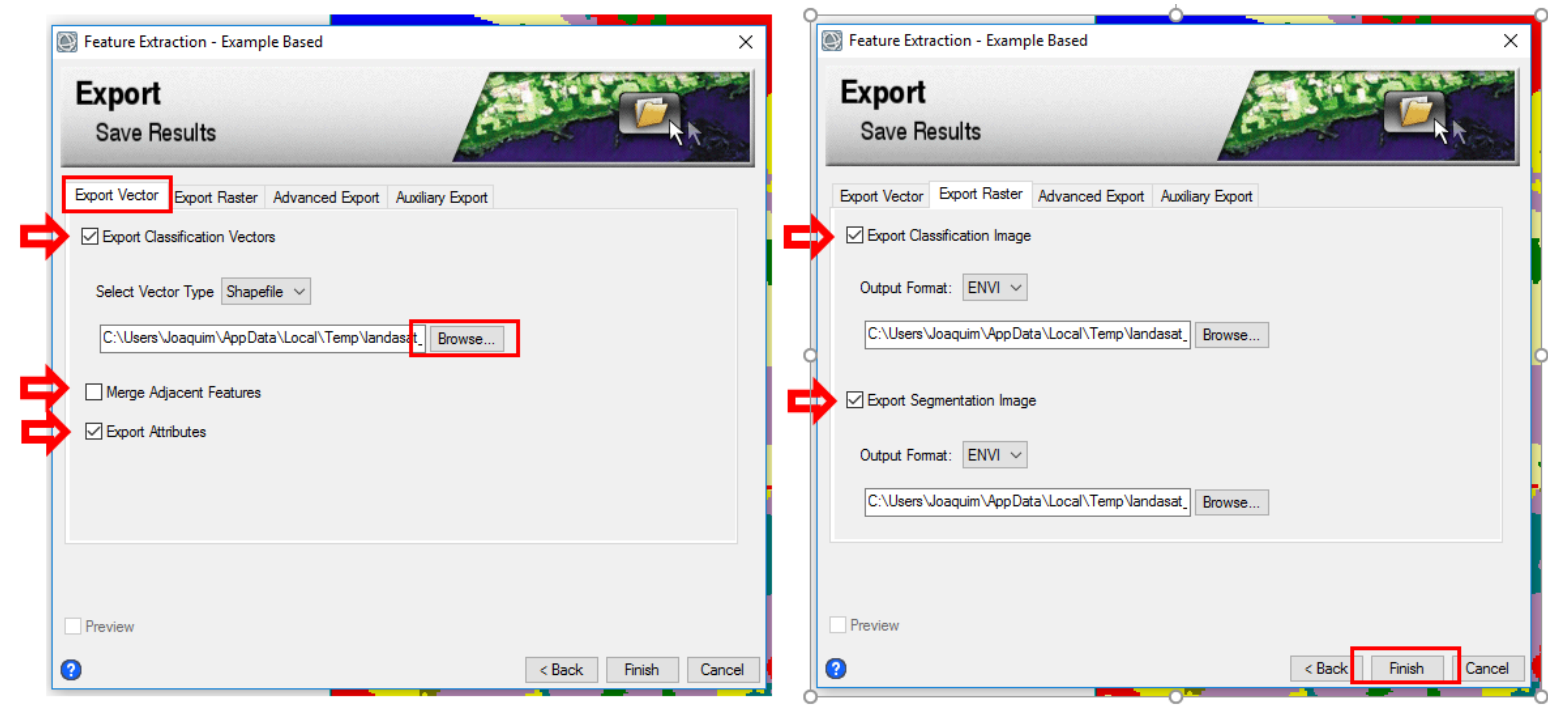
PARTE VII

\section{PÓS CLASSIFICAÇÃO}

\section{AVALIAÇÃO DA INCERTEZA EM MAPEAMENTOS - COEFICIENTE DE KAPPA E ÍNDICE DE EXATIDÃO GLOBAL}

Classificação é o processo de extração de informação em imagens para reconhecer padrões e objetos homogêneos que são utilizados para mapear áreas da superfície terrestre que correspondem aos temas de interesse. Em geral, o processo de classificação não é exato e, consequentemente, existe uma certa incerteza associada aos resultados produzidos (Rennó, 2016).

Existem vários tipos de incerteza e o significado atribuído ao termo incerteza aparece com diferentes interpretações na literatura: erro, ambiguidade ou imprecisão. Na classificação, a incerteza surge devido a diferentes fatores: resolução espacial (mistura de classes), definição de classes, escolha de amostras representativas, escolha de atributos representativos (bandas espectrais ou atributos derivados), escolha das funções discriminantes ou de pertinência (e de seus parâmetros), erros aleatórios e sistemáticos, etc (Rennó, 2016).

Para avaliar estas incertezas, existem uma série de métodos que possibilitam quantificar a incerteza de classificação. Aqui, serão estudados o Índice de Exatidão Global e o Coeficiente KAPPA, baseados na matriz de erros.

\section{AVALIAÇÃO DA INCERTEZA EM MAPEAMENTOS NO ENVI}

A. No ENVI 5.0, abra o programa e busque na toolbox o a pasta Classification > Post Classification. 


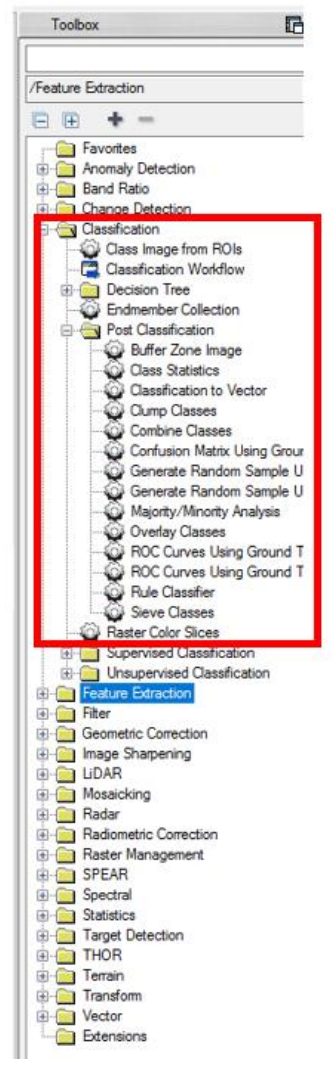

B. Dentro da pasta Post Classification, estão contidas uma série de ferramentas para avaliação da qualidade dos mapeamentos. Vale destacar, que para avaliação da incerteza em mapeamentos o delineamento amostral é de profunda importância, para evitar o enviesamento dos dados de controle.

C. De tal modo, há duas etapas principais, a primeira é a escolha dos pontos amostrais e a segunda é como serão colhidas amostras para avaliação de incerteza. Para execução do primeiro passo, existem diversos métodos para seleção dos pontos amostrais dentro da estatística probabilística e não probabilística.

D. Recomendamos, utilizar amostragem probabilística aleatória ou aleatória estratificada, existem uma serie de softwares que podem ser utilizados para gerar os pontos amostrais aleatórios, como 


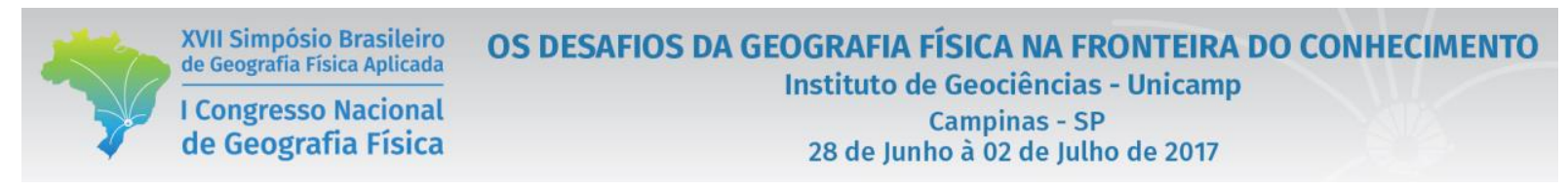

ArcGIS, QGIS, ENVI, entre outros, todavia não iremos nos delongar neste tema por não se tratar do assunto do curso.

E. A partir da seleção dos locais para amostragem, existem duas formas que prezam em garantir a veracidade e reduzir o enviesamento dos dados, a primeira, que é a mais recomendável é a realização de trabalho de campo para avaliação in loco do uso e manejo do solo. A segunda, seria a utilização de imagem de alta resolução espacial para avaliação do uso e manejo do solo. No caso o aplicativo Google Earth Pró é bastante eficiente neste quesito. Todavia, caso a amostragem seja por imagem de alta resolução, é necessário que a execução dos índices de avaliação de classificação seja realizada por especialista diferente do que executou a classificação da imagem, visando a garantia dos resultados.

F. Dentro do próprio ENVI 5.0, podemos criar as áreas para amostragem da classificação, utilizando as ferramentas, Generate Random Sample Using Ground Truth Image e Generate Random Sample Using Ground Truth ROIs que estão em destaque na figura abaixo.

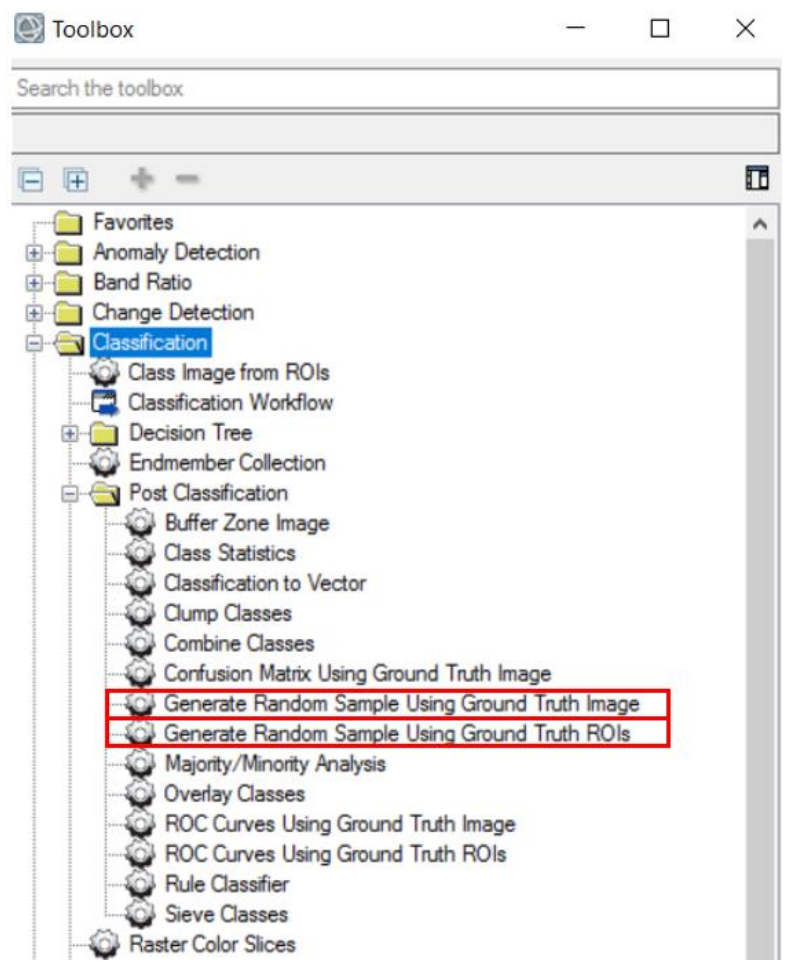

G. Porém utilizaremos o arquivo "amostras_validacao", onde já estão gerados os locais amostrais que utilizaremos para rodar os índices de avaliação de incertezas de classificação. 


$\begin{array}{cc}\begin{array}{c}\text { XVII Simpósio Brasileiro } \\ \text { de Geografia Fisica Aplicada }\end{array} & \text { OS DESAFIOS DA GEOGRAFIA FÍSICA NA FRONTEIRA DO CONHECIMENTO } \\ \begin{array}{l}\text { I Congresso Nacional } \\ \text { de Geografia Física }\end{array} & \begin{array}{c}\text { Campitituto de Geociências - Unicamp } \\ \text { CPP }\end{array} \\ 28 \text { de Junho à 02 de Julho de } 2017\end{array}$

H. Para realizarmos o Kappa, primeiro abra a imagem e o arquivo "amostras_validacao" clique na ferramenta Confusion Matrix Using ground Truth Image, como demonstra a figura abaixo.

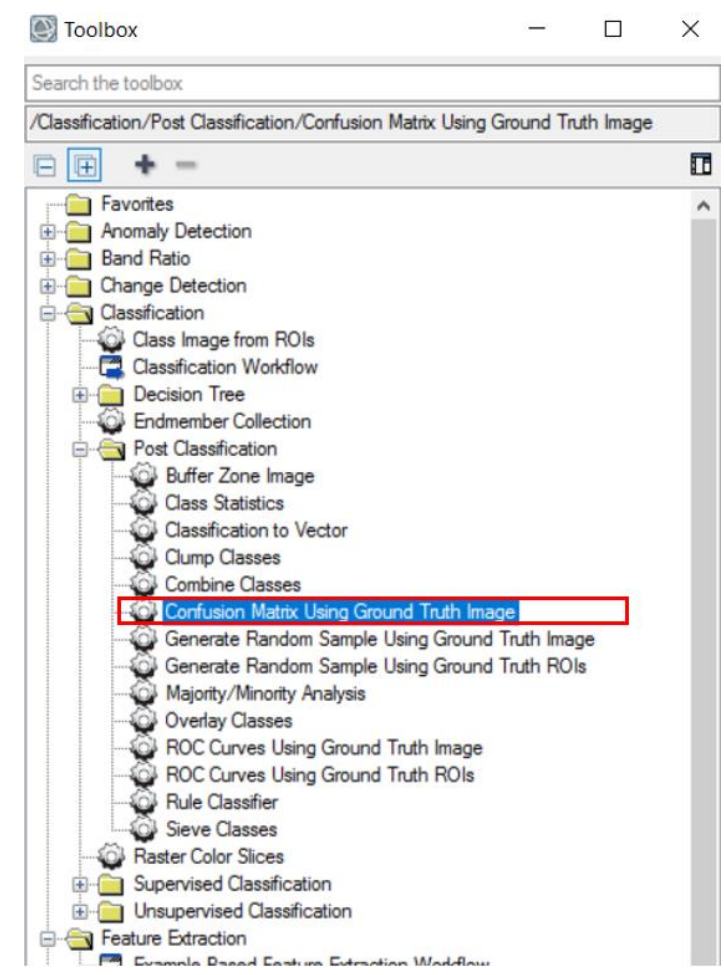

I. Irá abrir a janela Classification input file, clique no arquivo "amostras_validacao" e clique em OK. Você será direcionado para a janela Match Classes Parameter, nesta aba devem ser adicionados os ROIs criados, para cada classe de uso deve ser gerado um ROI com o nome igual das classes geradas na classificação supervisionada. Para adicionar as combinações entre as áreas de ROIs com a classificação da imagem gerada, na ciaxa Selection Ground Truth ROI selecione um dos usos e clique no seu correspondente na caixa Select Classification Image, e depois clique em Add combination, para linkar as duas classes. 

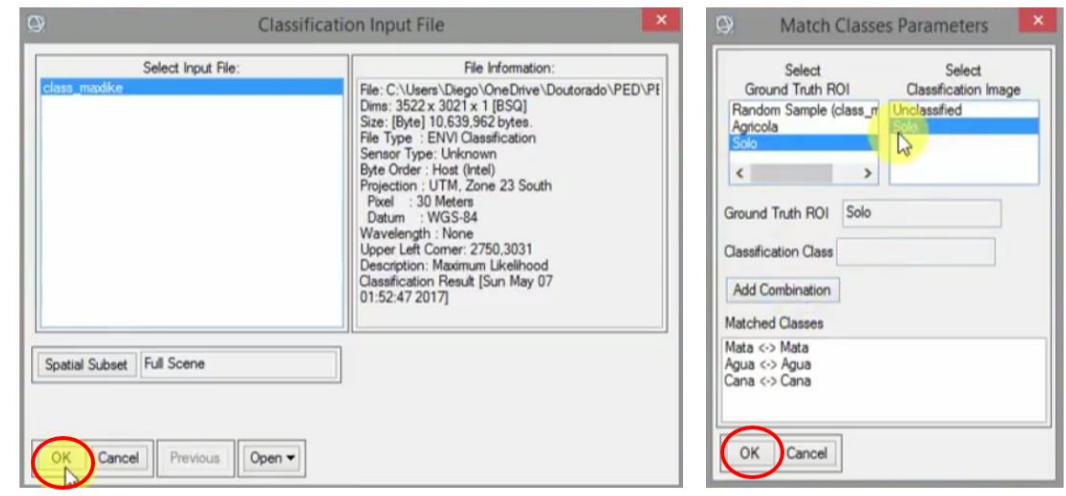

J. Depois de combinar todas as classes presentes no mapeamento clique em $O K$. Irá ser aberta a aba Confusion Matrix Parameter, selecione todas as opções e clique e Ok para gerar o relatório de avaliação da incerteza com os valores de Kappa, Exatidão Global e com a matriz de confusão. L. No relatório de avaliação da exatidão gerado, figura abaixo, vão ser produzidos o Índice de Exatidão Global destacado com a seta vermelha; o Coeficiente de Kappa com a seta azul; na matriz de erro, podemos observar na linha diagonal em vermelho o número de pixels ou objetos classificados nas linhas estão os valores de quantos destes objetos foram classificados erradamente em outra classe. Nos balões em vermelho temos respectivamente os Erros de comissão que representam a fração de valores que se prevê estarem em uma classe, mas não pertencem a essa classe. Eles são uma medida de falsos positivos. Erros de omissão representam a fração de valores que pertencem a uma classe, mas foram previstos em uma classe diferente. Eles são uma medida de falsos negativos. Destacados nos balões em azul temos $A$ precisão do produtor que é a probabilidade de que um valor em uma determinada classe tenha sido classificado corretamente e a precisão do usuário que é a probabilidade de um valor previsto em uma determinada classe realmente ser essa classe. A probabilidade é baseada na fração de valores corretamente previstos para o número total de valores previstos em uma classe (HARRIS GEOSPATIAL, 2017). No caso desta matriz, ela possui 100\% de acerto, isto não ocorre de fato. 


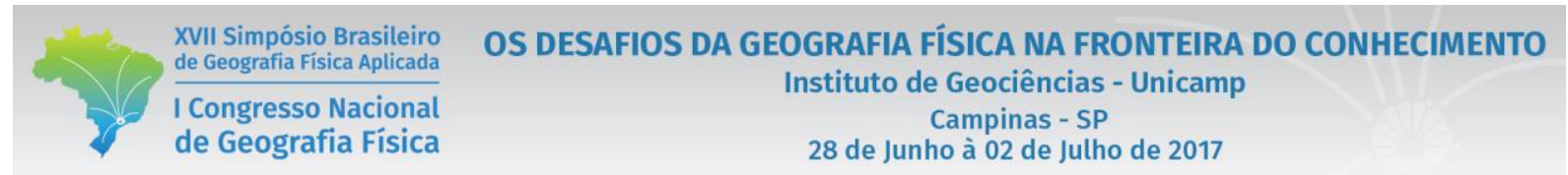

\begin{tabular}{|c|c|c|}
\hline \multicolumn{3}{|c|}{ Confusion Matrix Parameters } \\
\hline \multicolumn{3}{|c|}{ 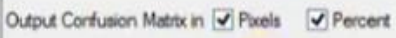 } \\
\hline \multicolumn{3}{|c|}{ Repot Accuracy Assesemert oy } \\
\hline OK & Concel & \\
\hline
\end{tabular}

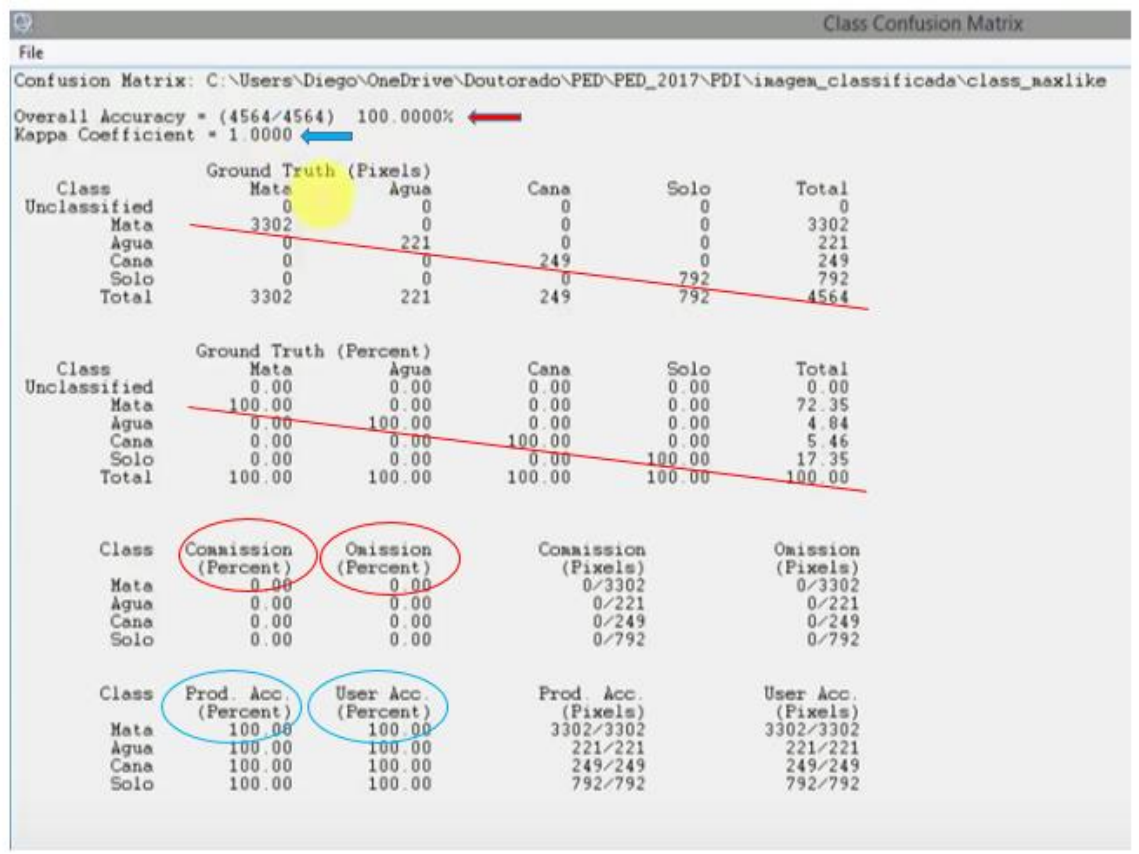




\section{REFERÊNCIAS BIBLIOGRÁFICAS}

AYER, J.E.B.; OLIVETTI, D.; MINCATO, E.L.; SILVA, M.L.N. Erosão hídrica em Latossolos Vermelhos distrófico. Pesquisa Agropecuária Tropical, Goiânia, v. 45, n. 2, p. 180-191, abr./jun. 2015.

CRÓSTA, A. P.. Processamento digital de imagens de sensoriamento remoto.Campinas: Unicamp, 1992

EMBRAPA MONITORAMENTO POR SATÉLITE. Disponível em: https://www.embrapa.br/monitoramento-por-satelite. Acesso em: 25/06/2017.

FITZ, P.R. Cartografia básica. São Paulo: oficina de textos, 2008. 143 p.

FLORENZANO, T. G. Iniciação em Sensoriamentio Remoto - $3^{a}$ ed. São Paulo: Oficina de Textos, 2011.

GONZALES, R.C.; WOODS, R.E. Processamento de Imagens Digitais. São Paulo: Edgar Blucher, 1992

HARRRIS GEOSPATIAL. Example-Based Classification. 2015. Disponível em:

https://www.harrisgeospatial.com/docs/Example_Based_Classification.html\#SelectInputFiles.

Acesso em: 25/06/2017.

HEYMANN, Y. Corine land cover technical guide. Luxembourg: Statistical Office of the European Communities - Eurostat, 1994.

IBGE. Manual técnico de uso da terra - $3^{\mathrm{a}}$ ed. Rio de Janeiro: IBGE, 2013.

JENSEN, J. R. Sensoriamento remoto do ambiente: uma perspectiva em recursos terrestres. Tradução: EPIPHANIO, J. C. N. et. al. São José dos Campos: Parênteses, 2009.

LILLESAND, T. M.; KIEFER, R. W.; CHIPMAN, J. W. Remore sensing and image interpretation $-6^{\mathrm{a}}$ ed. United States of America: Phoenix Color, 2008

MENEZES, P. R.; SANO, E. E. Classificação pixel a pixel e imagens. In.: MENEZES, P. R.; ALMEIDA, T. Introdução ao processamento de imagens de sensoriamento remoto. Brasília: UNB, 2012.

MOREIRA, M. A. Fundamentos de sensoriamento remoto e metodologias de aplicação $-4^{\mathrm{a}}$ ed. Viçosa: UFV, 2011.

NOVO, E. M. L. M. Sensoriamento remoto: princípios e aplicações - $4^{\mathrm{a}}$ ed. São Paulo: Edgar Blücher Ltda, 2010. 


\begin{tabular}{|c|c|}
\hline $\begin{array}{l}\text { XVII Simpósio Brasileiro } \\
\text { de Geografia Fisica Aplicada }\end{array}$ & $\begin{array}{c}\text { OS DESAFIOS DA GEOGRAFIA FÍSICA NA FRONTEIRA DO CONHECIMENTO } \\
\text { Instituto de Geociências - Unicamp }\end{array}$ \\
\hline $\begin{array}{l}\text { I Congresso Nacional } \\
\text { de Geografia Física }\end{array}$ & $\begin{array}{l}\text { Campinas - SP } \\
28 \text { de Junho à } 02 \text { de Julho de } 2017\end{array}$ \\
\hline
\end{tabular}

PONZONI, F. J.; SHIMABUKORO, Y. E.; KUPLICH, T. M. Sensoriamento remoto da vegetação $-2^{a}$ ed. São Paulo: Oficina de Textos, 2012. 